\title{
PERFORMANCE DEMONSTRATION PROGRAM PLAN FOR RCRA CONSTITUENT ANALYSIS OF SOLIDIFIED WASTES
}

REVISION O

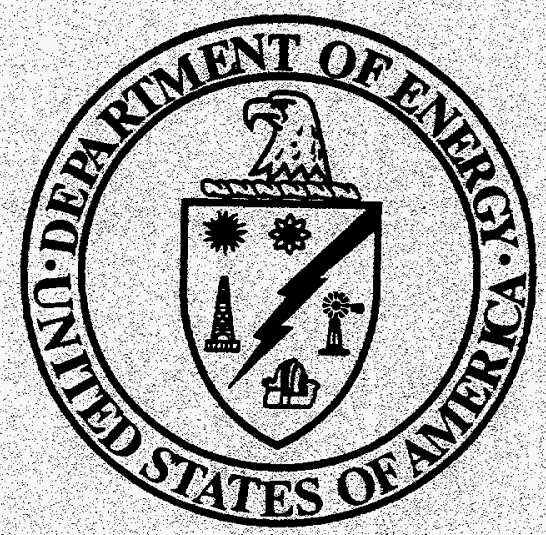

JUNE 1995

\section{U.S. DEPARTMENT OF ENERGY CARLSBAD AREA OFFICE}




\section{DISCLAIMER}

This report was prepared as an account of work sponsored by an agency of the United States Government. Neither the United States Government nor any agency thereof, nor any of their employees, make any warranty, express or implied, or assumes any legal liability or responsibility for the accuracy, completeness, or usefulness of any information, apparatus, product, or process disclosed, or represents that its use would not infringe privately owned rights. Reference herein to any specific commercial product, process, or service by trade name, trademark, manufacturer, or otherwise does not necessarily constitute or imply its endorsement, recommendation, or favoring by the United States Government or any agency thereof. The views and opinions of authors expressed herein do not necessarily state or reflect those of the United States Government or any agency thereof. 


\section{DISCLAIMER}

Portions of this document may be illegible in electronic image products. Images are produced from the best available original document. 


\title{
Performance Demonstration Program Plan for RCRA Constituent Analysis of Solidified Wastes
}

\section{DOE/CAO-95-1077}

\author{
Revision 0
}

Carlsbad Area Office

Published June 1995 
U.S. DEPARTMENT OF ENERGY CARLSBAD AREA OFFICE

PERFORMANCE DEMONSTRATION PROGRAM PLAN FOR RCRA CONSTITUENT ANALYSIS OF SOLIDIFIED WASTES

REVISION 0

June 1995

Concurred by:
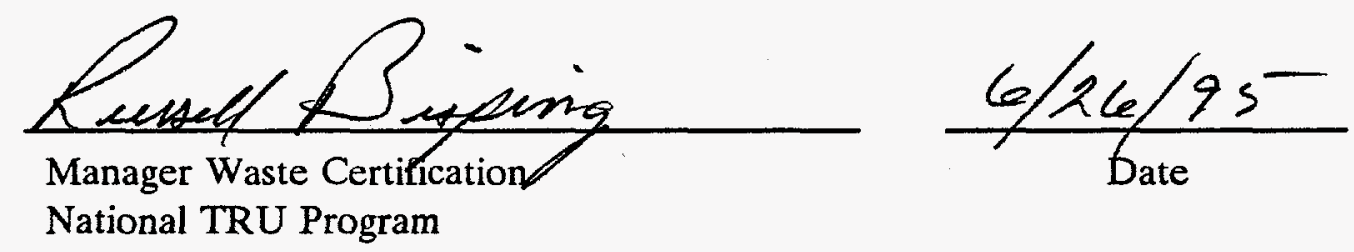

Concurred by:
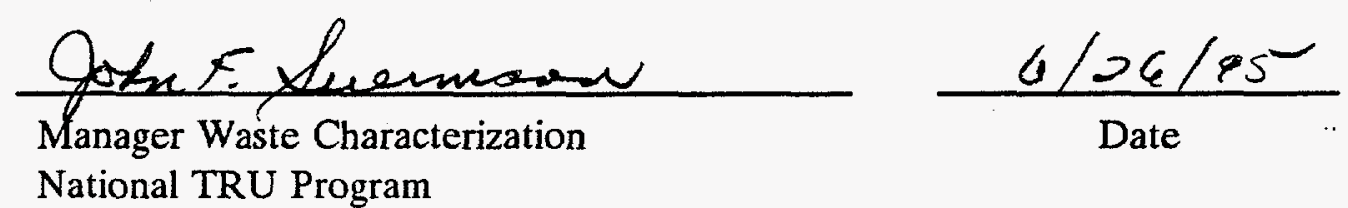

Approved by:
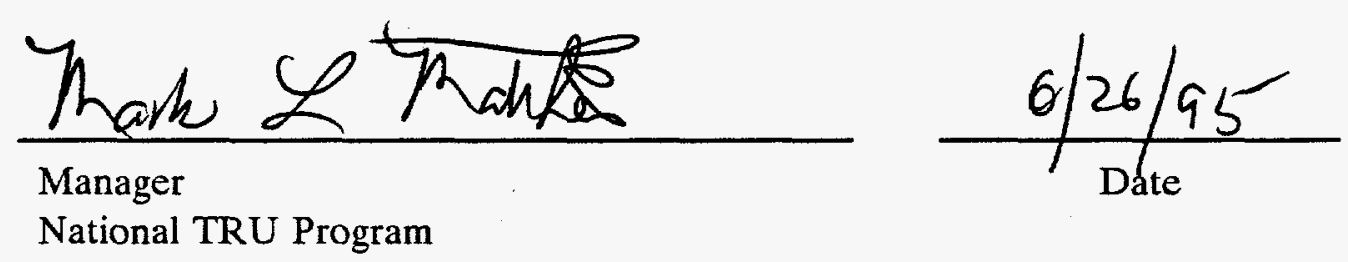


\section{CONTENTS}

ACRONYMS $\ldots \ldots \ldots \ldots \ldots \ldots \ldots \ldots \ldots \ldots \ldots \ldots \ldots \ldots \ldots \ldots \ldots \ldots \ldots \ldots$

1. SCOPE AND FREQUENCY $\ldots \ldots \ldots \ldots \ldots \ldots \ldots \ldots \ldots \ldots \ldots \ldots \ldots \ldots$

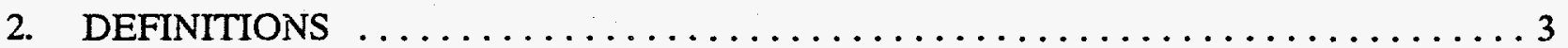

3. PROGRAM COORDINATION $\ldots \ldots \ldots \ldots \ldots \ldots \ldots \ldots \ldots \ldots \ldots \ldots \ldots \ldots \ldots \ldots \ldots$

4. PREPARATION OF PDP SAMPLES $\ldots \ldots \ldots \ldots \ldots \ldots \ldots \ldots \ldots \ldots \ldots \ldots$

5. ANALYTICAL AND DATA REPORTING REQUIREMENTS . . . . . . . . 11

5.1 Sample Receipt / Chain of Custody $\ldots \ldots \ldots \ldots \ldots \ldots \ldots \ldots \ldots \ldots \ldots$

$5.2 \quad$ Analysis $\ldots \ldots \ldots \ldots \ldots \ldots \ldots \ldots \ldots \ldots \ldots \ldots \ldots \ldots \ldots \ldots \ldots \ldots \ldots \ldots \ldots$



6. EVALUATION OF PERFORMANCE DATA ................. 14

6.1 Total Analysis of Volatile Organic Compounds (VOCs) -1 Analytes . . . . . . 14

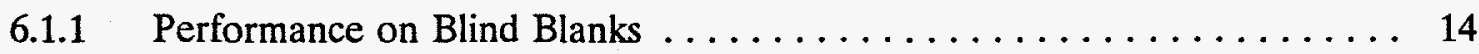

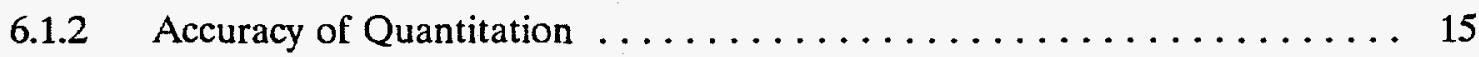

6.1 .3 Precision of Quantitation of Duplicates $\ldots \ldots \ldots \ldots \ldots \ldots \ldots \ldots \ldots$

6.1.4 Precision of Replicate Determinations $\ldots \ldots \ldots \ldots \ldots \ldots \ldots \ldots \ldots$

6.1.5 Overall Performance ........................ 17

6.2 Total Analysis of Semivolatile Organic Compounds (SVOCs) - 2 Analytes . . . . . 21

6.2.1 Performance on Blanks . . . . . . . . . . . . . . . . . 21

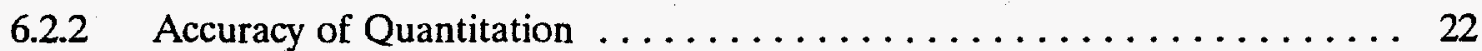

6.2.3 Precision of Quantitation of Duplicates $\ldots \ldots \ldots \ldots \ldots \ldots \ldots \ldots \ldots$

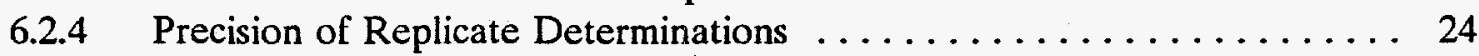

6.2 .5 Overall Performance ....................... 25

6.3 Analysis of Total Metals -3 Analytes $\ldots \ldots \ldots \ldots \ldots \ldots \ldots \ldots \ldots$

6.3.1 Performance on Blanks . . . . . . . . . . . . . . . . . 29

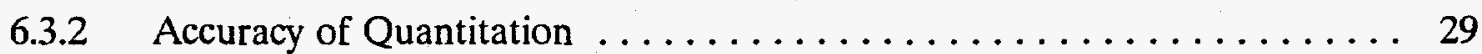

6.3.3 Precision of Quantitation of Duplicates $\ldots \ldots \ldots \ldots \ldots \ldots \ldots \ldots \ldots \ldots$

6.3.4 Overall Performance ........................ 31 
7. REPORTING OF PERFORMANCE DATA $\ldots \ldots \ldots \ldots \ldots \ldots \ldots \ldots$

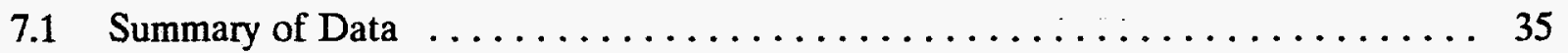

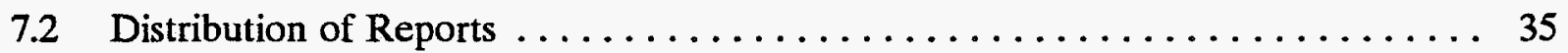

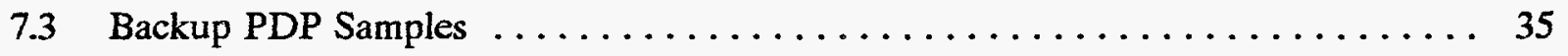

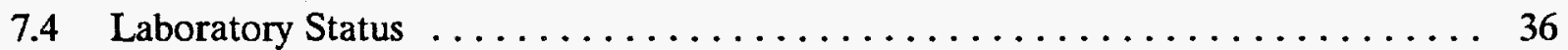

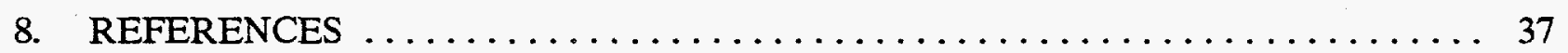

Appendix A-Sample Chain of Custody Form $\ldots \ldots \ldots \ldots \ldots \ldots \ldots \ldots \ldots \ldots \ldots$

Appendix B-Sample Data Reporting Form $\ldots \ldots \ldots \ldots \ldots \ldots \ldots \ldots \ldots \ldots$. . . . . . .

TABLES

1. Total volatile organic compounds target analyte list $\ldots \ldots \ldots \ldots \ldots \ldots \ldots$

2. Total semivolatile organic compound target analyte list $\ldots \ldots \ldots \ldots \ldots \ldots \ldots$

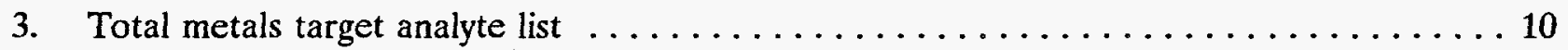




\section{ACRONYMS}

\begin{tabular}{|c|c|}
\hline $\mathrm{COC}$ & chain of custody \\
\hline DOE & Department of Energy \\
\hline $\mathrm{DOE} / \mathrm{CAO}$ & DOE Carlsbad Area Office \\
\hline GC/MS & gas chromatography/mass spectrometry \\
\hline IDL & instrument detection limit \\
\hline MDL & method detection limit \\
\hline MS & matrix spike \\
\hline MSD & matrix spike duplicate \\
\hline OPS & operations \\
\hline PCB & polychlorinated biphenyl \\
\hline PDP & Performance Demonstration Program \\
\hline PRDL & Program Required Detection Limit \\
\hline PRQL & Program Required Quantitation Limit \\
\hline QA & quality assurance \\
\hline QAO & Quality Assurance Objective \\
\hline QA/QC & quality assurance/quality control \\
\hline QAPP & Quality Assurance Program Plan \\
\hline QC & quality control \\
\hline$\% \mathrm{R}$ & percent recovery \\
\hline RCRA & Resource Conservation and Recovery Act \\
\hline RPD & relative percent difference \\
\hline RSD & relative standard deviation \\
\hline
\end{tabular}


SPT Special Purpose Test

SVOC semivolatile organic compound

TA target analyte

TIC tentatively identified compound

TRU transuranic

VOC volatile organic compound

VTSR validated time of sample receipt

WIPP Waste Isolation Pilot Plant

WIPP-WAG Waste Acceptance Criteria for the Waste Isolation Pilot Plant (DOE 1991) 


\section{Performance Demonstration Program Plan for the RCRA Constituent Analysis of Solidified Wastes}

\section{SCOPE AND FREQUENCY}

Performance Demonstration Programs (PDPs) are designed to help ensure compliance with the Quality Assurance Objectives (QAOs), identified in the Transuranic (TRU) Waste Characterization Quality Assurance Program Plan (QAPP) (DOE 1994a) for the Waste Isolation Pilot Plant (WIPP). The PDPs are intended for use by the Department of Energy (DOE) Carlsbad Area Office (CAO) to assess and approve the laboratories and other measurement facilities supplying services for the characterization of WIPP TRU waste. The PDPs may also be used by $\mathrm{CAO}$ in qualifying laboratories proposing to supply additional analytical services that are required for other than waste characterization, such as WIPP site operations.

Each PDP is defined in its respective PDP Plan, which describes the detailed elements that comprise the program, including the nature of the test materials and the analyses required. The PDP Plan also identifies the criteria that will be used for the evaluation of laboratory performance, the responsibilities of the Program Coordinator, and the responsibilities of the participating laboratories. The CAO is responsible for ensuring the implementation of this plan by designating the Program Coordinator and by providing technical oversight and coordination for the program. In addition to the PDP described in the present document, two other PDPs are active. These are described in their respective PDP Plans: the Performance Demonstration Program Plan for Nondestructive Assay for the TRU Waste Characterization Program (DOE 1994b), and the Performance Demonstration Program Plan for the Analysis of Simulated Headspace Gases for the TRU Waste Characterization Program, (DOE 1995a).

The purpose of this PDP is to test laboratory performance for the analysis of solidified waste samples for TRU waste characterization. This performance will be demonstrated by the successful analysis of blind audit samples of simulated, solidified TRU waste according to the criteria established in this plan. Blind audit samples (hereinafter referred to as PDP samples) will be used as an independent means to assess laboratory performance regarding compliance with the QAPP QAOs. The concentration of analytes in the PDP samples will address levels of regulatory concern and will encompass the range of concentrations anticipated in actual waste characterization samples. Analyses that are required by the WIPP to demonstrate compliance with various regulatory requirements and which are included in the PDP must be performed by laboratories that demonstrate acceptable performance in the PDP. These analyses are referred to as WIPP analyses and the samples on which they are performed are referred to as WIPP samples for the balance of this document.

In order to obtain or retain their qualification to perform analytical measurements for the WIPP, all participating laboratories must demonstrate acceptable performance on a semiannual basis. Single blind samples will be distributed to participating laboratories every $26 \pm 3$ weeks. The criteria for acceptable performance are given in Section 6 of this PDP. The PDP samples 
must be analyzed using the same methods and under the same conditions of radioactivity confinement that the laboratory anticipates using for the analysis of WIPP samples. These methods must have been developed and internally approved within the specifications of the QAPP. [See also the WIPP Waste Characterization Program Sampling and Analysis Methods Manual (DOE 1994c) for additional guidance.] Only the methods actually used in the PDP will be considered acceptable to support the analysis of WIPP samples. The data generated as a result of the performance demonstration will indicate the appropriateness of the method used as well as the performance of the laboratory.

Laboratories may elect to qualify more than one method for an analyte or split analytes between different methods. For example, three organic analytes may be analyzed by the methods for volatile compounds or by the methods for semi-volatile compounds. If the laboratory wishes to have the option to use either method for waste characterization then both methods must be used to determine these analytes in the PDP. If only one method is qualified, the laboratory will not be approved for the analysis of these analytes by the alternate method. When submitting both method performance and PDP data, each laboratory must indicate which compounds are the intended target analytes for each submitted method. 


\section{DEFINITIONS}

ACCURACY - The degree of agreement between a measured value and an accepted reference or the true value. Accuracy is determined as the percent recovery (\%R).

ACTION LIMIT - A numerical criterion that must be met for the analysis of an individual analyte, e.g., blank or background concentration. Failure to meet this criterion may result in a conclusion that the laboratory is unable to quantitate for a specific individual analyte.

ACTION LEVEL - A numerical criterion that must be met for a type of analysis e.g., a fraction of \%Rs that must fall within the respective QAOs. Failure to meet this criterion may result in a conclusion that the laboratory is unable to adequately perform a specific type of analysis.

ANALYSIS DATE/TIME - The date and military time (24-hour clock) of the introduction of the sample, standard, or blank into the analysis system.

ANALYTE - The element, ion, or compound an analysis seeks to determine; the element of interest.

ANALYTICAL METHOD - The sample preparation and instrumentation procedures or steps that must be performed to estimate the quantity of analyte in a sample.

AUDIT - A planned and documented investigative evaluation of an item or process to determine the adequacy and effectiveness as well as compliance with established procedures, instructions, drawings, and/or other applicable documents.

BLIND AUDIT SAMPLE - A sample of known composition provided as a single-blind sample to the analytical laboratory. Used by DOE to evaluate analytical laboratory performance. Blind audit samples are distributed to participating laboratories as part of the PDP.

CHAIN OF CUSTODY (COC) - A set of procedures established to ensure that the integrity of the sample and that of the sample data are maintained.

CORRECTIVE ACTION - Measures taken to rectify conditions adverse to quality or schedule and, where necessary, to preclude repetition.

DUPLICATE - A second aliquot of a sample that is treated the same as the original sample to determine the precision of the method.

INSTRUMENT DETECTION LIMIT (IDL) - The minimum signal that an instrument can detect with $99 \%$ confidence that the analyte concentration is greater than zero.

INTERFERENTS - Substances that affect the analysis for the element or compound of interest. 
LABORATORY BLANK - An analyte-free matrix to which all reagents are added in the same volumes or proportions as used in sample analysis. The laboratory blank is used to assess contamination resulting from the laboratory sample preparation and analytical process.

LABORATORY CONTROL SAMPLE - A control sample of known composition. Laboratory control samples are analyzed using the same analytical methods employed for the program samples received.

METHOD DETECTION LIMIT (MDL) - The minimum concentration of an analyte that can be measured and reported for a given method with 99-percent confidence that the analyte concentration is greater than zero. MDL is determined from analysis of a sample in a given matrix type containing the analyte of interest. The maximum values for MDLs permissible for the program are presented in Tables 1 and 2.

PDP SAMPLE - A blind audit sample prepared specifically for use in the PDP.

PRECISION - A measure of mutual agreement among individual measurements of the same property made under prescribed similar conditions; often expressed as a standard deviation or relative percent difference $(R P D)$.

PROCEDURE - A detailed, step-by-step description of the sequence of actions to be followed in order to perform a given task. If followed in sequence, a procedure provides enough information that a trained person could complete the covered task without additional information.

PROGRAM COORDINATOR - A CAO-designated organization that administers and coordinates PDP functions, such as PDP sample component preparation, subcontractor oversight, scheduling, scoring, and report summary generation.

PROGRAM REQUIRED DETECTION LIMIT (PRDL) - The maximum values for instrument detection limits permissible for the program. PRDLs are presented in Table 3.

PROGRAM REQUIRED QUANTITATION LIMIT (PRQL) - Minimum level of analyte quantitation acceptable. An analyte PRQL should be a minimum of three times the MDL or IDL. PRQLs are presented in Tables 1 and 2.

QUALITY ASSURANCE (QA) - All those planned and systematic actions necessary to provide adequate confidence that a facility, structure, system, or component will perform satisfactorily and safely in service. The goals of QA are to ensure that research, development, demonstration, scientific investigations, and production activities are performed in a controlled manner; that components, systems, and processes are designed, developed, constructed, tested, operated, and maintained according to engineering standards, quality practices, and Technical Specifications/ Operational Safety Requirements; and that resulting technology data are valid, defensible, and retrievable. QA includes quality control (QC), which comprises all those actions necessary to control and verify the features and characteristics of a material, process, product, or service to specified requirements. 
QUALITY ASSURANCE OBJECTIVES (QAOs) - The characteristics of data that are associated with its ability to satisfy a given purpose or objective. The characteristics of major importance are accuracy, precision, completeness, representativeness; and comparability.

RECOVERY - The numerical ratio of the amount of analyte measured by the laboratory method divided by the known amount of analyte added to the matrix (i.e., spiked sample) to be analyzed. Usually expressed as a percent $(\% \mathrm{R})$.

SAMPLE - A portion of material to be analyzed that is contained in single or multiple containers and identified by a unique sample number.

TARGET ANALYTES - Those volatile organic compounds (VOCs), semivolatile organic compounds (SVOCs), metals, and nonmetallic elements identified by the program as analytes. Target analytes for the program are listed in Tables 1-3.

TENTATIVELY IDENTIFIED COMPOUNDS (TICS) - Nontarget compounds identified using gas chromatography/mass spectrometry (GC/MS). These reported concentrations will have a higher uncertainty associated with them than the reported target analyte concentrations.

TRANSURANIC (TRU) WASTES - Laboratory and process wastes that contain alpha-emitting radionuclides of atomic number greater than 92 (e.g., the radioactive isotopes of plutonium), have half-lives longer than 20 years, and are present in concentrations greater than 100 nanocuries per gram of waste.

VALIDATED TIME OF SAMPLE RECEIPT (VTSR) - The date on which a sample is received at the analytical facility, as recorded on the shipper's delivery receipt and sample traffic report.

VOLATILE ORGANIC COMPOUNDS (VOCs) - For the purposes of the program, those VOCs listed in Table 1 and any additional compounds tentatively identified by the VOC analytical procedures used to satisfy program requirements. 


\section{PROGRAM COORDINATION}

Ensuring the administration and coordination of the PDP's semiannual testing program will be the responsibility of the CAO. The CAO designated Program Coordinator will provide management of the interlaboratory performance demonstration program. For the interlaboratory PDP, the Program Coordinator will:

- Ensure the preparation and distribution of the PDP samples.

- Receive, review, score, and compile the analytical data.

- Report performance data as specified within this document.

The Program Coordinator will maintain a controlled list of the laboratories participating in the semiannual testing program. Laboratories required to participate in the PDP will be designated by the CAO. Laboratories in the PDP that are not required to participate but that desire to do so may petition the CAO to be permitted to participate in the PDP. Participation by laboratories not actively engaged in characterization of TRU wastes will be at the discretion of CAO.

Each participating laboratory will be required to provide the Program Coordinator with the name, telephone number, fax number, and address of the contact persons responsible for administrative communications for the PDP. Each participating laboratory will also be required to provide an address suitable for express package delivery services for receipt of PDP samples. 


\section{PREPARATION OF PDP SAMPLES}

The PDP blind audit samples are prepared to cover the analytes of concern to the program and their range of expected concentrations. These analytes and associated QA objectives are listed in Tables 1-3. Individual analytes may be present in concentrations ranging from approximately two times the PRDL/MDL to many times the PRQL. Appropriate blanks for each component will also be prepared. Final analyte concentrations in the PDP samples are left to the discretion of the Program Coordinator. In addition, individual samples will not be limited to any specific number of analytes nor to a specific range of concentrations.

Each distribution for VOCs or SVOCs will contain five (5) or more spiked samples and an appropriate number of blanks. Two of the spiked samples will be designated as the matrix spike (MS) and matrix spike duplicate (MSD). For VOCs and SVOCs, each sample will be supplied pre-weighed in a separate container. The entire sample shall be consumed for each analysis (e.g., the entire contents of the SVOC container must be extracted). For VOCs, the alcohols, ketones, and pyridine (if any) will be supplied in a separate container from the balance of the VOCs. Each distribution will also contain at least one spiked sample of a noninterfering matrix and any corresponding blanks.

Each distribution for metals will contain a blank and three (3) or more spiked samples. The sample to be used to prepare the MS and MSD will be designated. Sufficient sample weight will be provided for each of the metals spiked samples to permit multiple aliquots to be withdrawn. Each distribution will also contain a spiked sample of a noninterfering matrix and a corresponding blank.

The Program Coordinator shall ensure delivery of the PDP samples to each of the laboratories participating in the interlaboratory PDP. The Program Coordinator will keep all participants informed of developing PDP schedules and will give at least 2 weeks formal notification of the exact PDP sample shipping date to all participating laboratories. The PDP samples will be sent to the attention of those individuals and to the addresses previously provided to the Program Coordinator. Changes may be made to the addressees by written notification to the Program Coordinator (with a copy to $\mathrm{CAO}$ ) at least 48 hours before the scheduled shipping date.

On request, the Program Coordinator will make aliquots of the gross sample matrix or the recipe for its preparation available to program participants. 
Table 1. Total volatile organic compounds target analyte list.

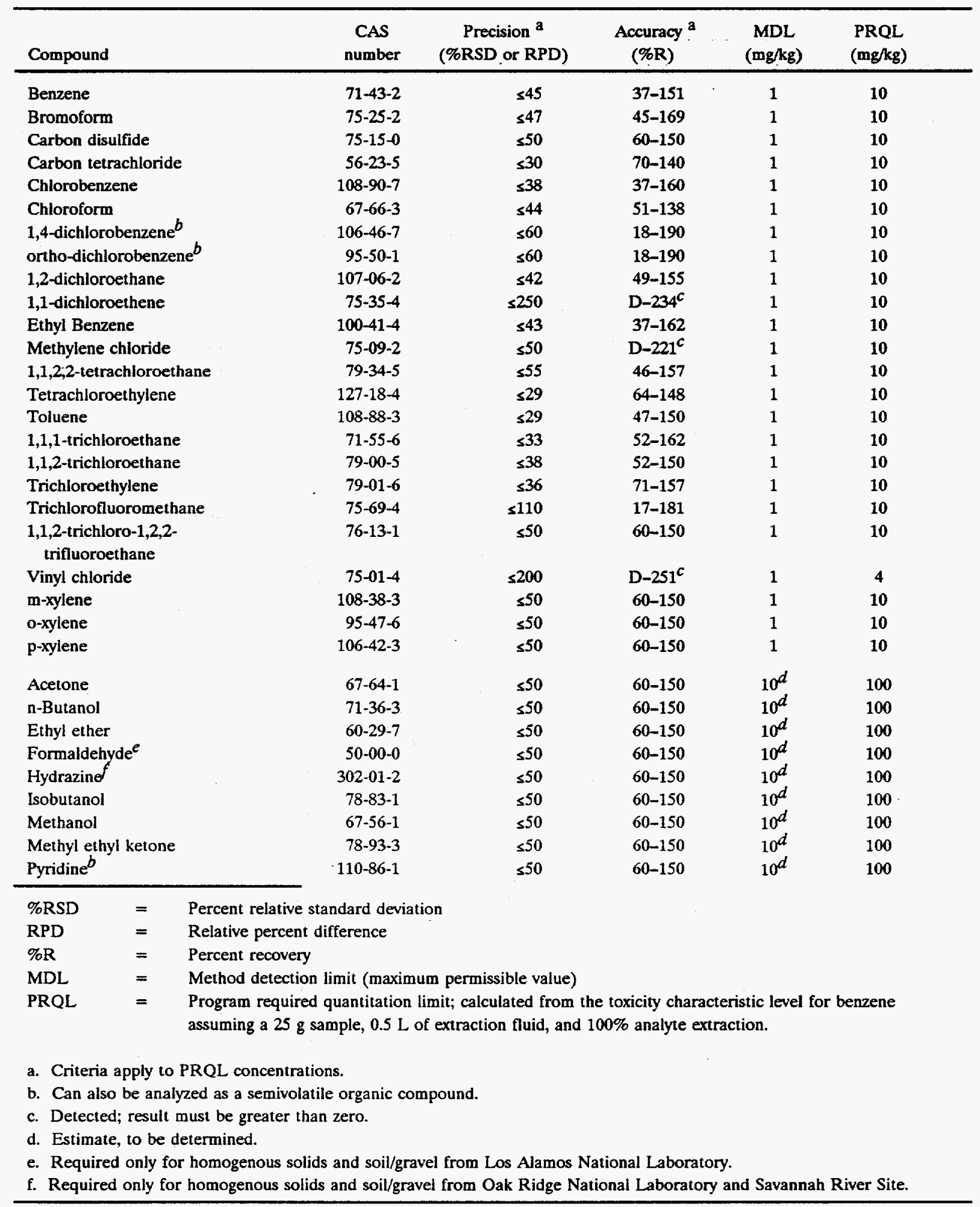


Table 2. Total semivolatile organic compound target analyte list.

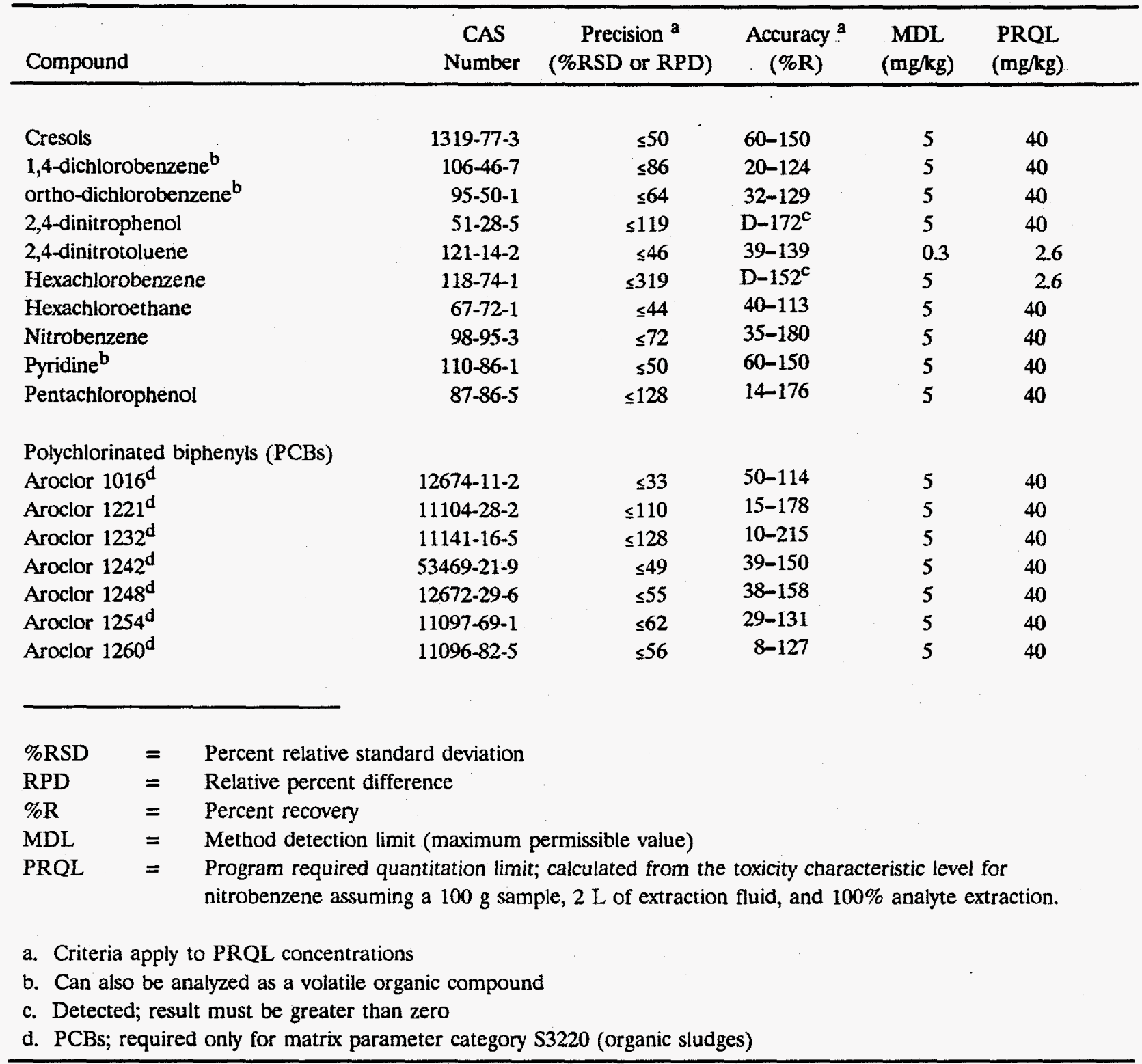


Table 3. Total metals target analyte list.

\begin{tabular}{lccccc}
\hline Analyte & CAS Number & $\begin{array}{c}\text { Precision } \\
(\% \text { RSD or RPD) }\end{array}$ & $\begin{array}{c}\text { Accuracy } \\
(\% \mathrm{R})^{\mathrm{b}}\end{array}$ & $\begin{array}{c}\text { PRDL } \\
(\mu \mathrm{g} / \mathrm{L})\end{array}$ & $\begin{array}{c}\text { PROL } \\
(\mathrm{mg} / \mathrm{kg})\end{array}$ \\
\hline Antimony & $7440-36-0$ & $\leq 30$ & $60-140$ & 100 & 100 \\
Arsenic & $7740-38-2$ & $\leq 30$ & $60-140$ & 100 & 100 \\
Barium & $7440-39-3$ & $\leq 30$ & $60-140$ & 2,000 & 2,000 \\
Beryllium & $7440-41-7$ & $\leq 30$ & $60-140$ & 100 & 100 \\
Cadmium & $7440-43-9$ & $\leq 30$ & $60-140$ & 20 & 20 \\
Chromium & $7440-47-3$ & $\leq 30$ & $60-140$ & 100 & 100 \\
Lead & $7439-92-1$ & $\leq 30$ & $60-140$ & 100 & 100 \\
Mercury & $7439-97-6$ & $\leq 30$ & $60-140$ & 4.0 & 4.0 \\
Nickel & $7440-02-0$ & $\leq 30$ & $60-140$ & 100 & 100 \\
Selenium & $7782-49-2$ & $\leq 30$ & $60-140$ & 20 & 20 \\
Silver & $7440-22-4$ & $\leq 30$ & $60-140$ & 100 & 100 \\
Thallium & $7440-28-0$ & $\leq 30$ & $60-140$ & 100 & 100 \\
Vanadium & $7440-62-2$ & $\leq 30$ & $60-140$ & 100 & 100 \\
Zinc & $7440-66-6$ & $\leq 30$ & $60-140$ & 100 & 100 \\
& & & &
\end{tabular}

$\begin{array}{lll}\% \mathrm{RSD} & = & \text { Percent relative standard deviation } \\ \mathrm{RPD} & = & \text { Relative percent difference } \\ \% \mathrm{R} & = & \text { Percent recovery } \\ \text { PRDL } & = & \text { Program required detection limit (i.e., maximum permissible value for instrument detection limit) } \\ \text { PRQL } & = & \text { Program required quantitation limit. }\end{array}$

a. $\leq 30 \%$ control limits apply when sample and duplicate concentrations are $\geq 10 \times$ IDL for inductively coupled plasmaatomic emission spectrometry (ICP-AES) and atomic absorption (AA) techniques, and $100 \times$ IDL for ICP-mass spectrometry (MS). If either are less than $10 \times \mathrm{IDL}$, the absolute difference between the two values shall be less than or equal to the PRDL.

b. Applies to recovery of the blind spiked target analytes (TAs) in the PDP samples. The matrix spike/matrix spike duplicate (MS/MSD) \%R requirement is 80-120\%. The accuracy limits in Table 15-1 of the QAPP apply only to laboratory control samples.

c. PRDL set such that the concentration in solution is a factor of 10 below the PRQL for $100 \%$ solid samples, assuming a $100 \mathrm{X}$ dilution during digestion. 


\section{ANALYTICAL AND DATA REPORTING REQUIREMENTS}

This section describes activities required of the participating laboratories with respect to PDP sample receipt, analysis, and reporting.

\subsection{Sample Receipt / Chain of Custody}

5.1.1 Immediately on receipt of the samples, locate the Delivery/Chain-of-Custody (COC) Record.

5.1.2 Verify that the samples actually received match those listed on the COC form both by serial number and physical description. Verify that the samples have not been damaged during shipping.

a. If there is a discrepancy, notify the Program Coordinator immediately. Maintain COC control over the samples and await further instructions.

b. If there are no discrepancies, indicate receipt by signing the Delivery/COC Record at the appropriate location.

5.1.3 Return a copy of the Delivery/COC Record to the shipper. Retain the original as the $\mathrm{COC}$ record for the samples. Site-specific $\mathrm{COC}$ procedures shall be initiated upon receipt of the PDP samples. It is the responsibility of the participating laboratories to ensure appropriate COC within their facilities. The COC form provided in Appendix A may be used for internal COC if appropriate.

\subsection{Analysis}

5.2.1 Analyze the contents of each sample using the procedures that have been internally demonstrated and approved and that are planned for use in the WIPP TRU waste characterization program.

5.2.2 Spike all MSs and MSDs at the PRQL for the respective target analytes. Use the following table to determine the minimum number of target analytes to spike for each class of analytes.

\begin{tabular}{cc}
\hline Type of analysis & Minimum no. of spiked analytes \\
\hline VOCs & 5 \\
SVOCs & 3 \\
SVOCs + PCBs & $3+1$ PCB \\
Metals & All \\
\hline
\end{tabular}

5.2.3 Analyses should be completed and reported as soon as possible, but in any case must be forwarded to the Program Coordinator within 28 calendar days after sample receipt. 
5.2.4 If a participating laboratory's analyses will not be reported by the due date and they desire an extension, they must notify the Program Coordinator in writing as soon as possible and request that an extension be granted. The Program Coordinator cannot grant an extension; however, they will request that the $\mathrm{CAO}$ grant an extension. The Program Coordinator will notify the laboratory of the status of their request. All extensions must be requested and granted before the due date. If an extension has not been granted before the due date, the Program Coordinator may make the concentrations of analytes in any of the PDP samples public at any time thereafter. Any laboratories that had not yet reported will then not be able to use those data to qualify for analysis of WIPP samples.

\subsection{Reporting}

5.3.1 Each PDP sample shall be analyzed for the analytes designated for that type of sample. A summary of all analytes listed in Tables 1 through 3 that are detected for all analyses will be sent by the participating laboratories to the Program Coordinator. The concentrations of any detected analytes are to be reported. The following specifications apply to the summary report:

5.3.1.1 Reports shall be forwarded directly to the Program Coordinator. Express mail or overnight delivery service is preferred but in any case all analytical reports to the Program Coordinator shall be postmarked or shipped by an overnight delivery service no later than 28 calendar days after VTSR.

5.3.1.2 Analytical reports shall be submitted for each sample received and for laboratory blanks and MS/MSDs run in association with the PDP samples.

5.3.1.3 Reports shall consist of at least the following information for each determination:

- Identification of the reporting laboratory

- Identification of the PDP Distribution Cycle and program component (e.g., VOC, metals, etc.) for which the data are being reported

- Identity of the sample by the serial number from the COC form

- Any additional identification assigned to the sample by the laboratory

- Identification of the procedures (i.e., preparation and determination) used for the analysis of each analyte

- Identity and concentration of each analyte identified

- Identification of any target analyte listed in Tables 1 or 2 for which the laboratory intentionally did not analyze the PDP sample. (e.g., if pyridine was analyzed only in the VOC PDP sample, pyridine should be listed on the SVOC report as "Not Analyzed as an SVOC.") 
- Date and time of analysis.

5.3.1.4 The results of each of the individual analyses must be reported.

5.3.1.5 The form given in Appendix B or a reasonable facsimile should be used to report the data to the Program Coordinator. The total number of pages in the report shall be indicated.

5.3.1.6 The report shall include a copy of the COC forms for the samples as they existed at the time of reporting.

5.3.1.7 Corrections to data will be accepted if received in writing before or on the report due date. Data may also be corrected by FAX up to 8:00 PM (eastern time zone) on the report due date, if followed by express mail or overnight courier transmission of the original hard copy. Verbal corrections to data will not be accepted.

5.3.1.8 The reports shall be signed by a laboratory staff member assigned this responsibility. Reports should contain any other information that the laboratory feels is relevant to the data evaluation.

5.3.1.9 The concentrations of all compounds that exceed the PRDL or MDL must be qualitatively identified. All compounds present at concentrations that exceed a calibration range or the PRQL must be quantified even if multiple dilutions of the sample must be analyzed. (See Tables 1-3 for PRDLs and MDLs). There is no requirement that concentrations of compounds and/or metals in the PDP samples be limited to any specific ratio range. (The Program Coordinator will ensure that the ratios of analytes are not so large as to be likely to cause instrument contamination.)

5.3.1.10 Concentrations must be reported in $\mathrm{mg} / \mathrm{kg}$ using sample reporting criteria specified in the QAPP. The weight basis for the PDP samples should be reported "as received."

5.3.1.11 Any additional instructions that accompany the PDP samples will also be followed (e.g., instructions for handling the noninterfering matrix). 


\section{EVALUATION OF PERFORMANCE DATA}

Laboratory performance will be evaluated on a point score system. Analytical performance will be evaluated separately for VOCs, SVOCs, and metals. Analytical data from the analysis of the noninterfering matrix must be reported but will not be scored. These data may be used in interpreting the significance of anomalous or incorrect data reported for the other PDP samples.

The acceptance criteria for the laboratories will be based on the requirements of this PDP.

\subsection{Total Analysis of Volatile Organic Compounds (VOCs) - Table 1 Analytes}

VOC analysis performance will be evaluated in the areas of performance on blanks, accuracy, precision, and correct detection and identification of TICs.

\subsubsection{Performance on Blind Blanks}

6.1.1.1 Purpose. Analytical results for blanks are used to determine the presence of contamination problems and to quantify those problems if any exist.

6.1.1.2 Criteria. The criterion for blank performance is that none of the target analytes should be present in the blank analyses at levels exceeding 50\% of the PRQL.

6.1.1.3 Evaluation Method. Acceptable blank performance is based on the data for all detected target analytes and the percent of their concentrations relative to the PRQL for that compound calculated as follows:

$R B T_{A}=\frac{C B_{A}}{P R Q L_{A}} \times 100$

where

$$
\begin{aligned}
& \mathrm{RBT}_{\mathrm{A}}=\text { amount of compound A calculated in blank as percent of the PRQL } \\
& \mathrm{CB}_{\mathrm{A}}=\text { concentration of compound } \mathrm{A} \text { in blank }(\mathrm{mg} / \mathrm{kg}) \\
& \mathrm{PRQL}_{\mathrm{A}}=\text { required quantitation limit for compound } \mathrm{A}(\mathrm{mg} / \mathrm{kg}) .
\end{aligned}
$$

6.1.1.4 Actions. If all of the participating laboratories report a specific analyte to be present in the blank at levels exceeding $50 \%$ of the PRQL, the blank will be considered contaminated and the analyte data will be judged unusable and deleted from consideration in the performance criteria for that particular performance demonstration. This conclusion will be based on a comparison of the mean and standard deviation of the values reported by the participants to the contamination criteria (i.e., 50\% of the PRQL) using a single-tailed " $\mathrm{t}$ " test at the $95 \%$ confidence level. If there are insufficient participants to perform an adequate " $t$ " test, data for individual compounds may still be judged inappropriate for use according to Section 6.1.5.5. 
6.1.1.4.1 For any compound for which the $\mathrm{RBT}_{\mathrm{A}}$ exceeds $50 \%$, the laboratory will be judged to have exceeded an action limit for compound $A$. Data for that compound will be identified as unacceptable by the Program Coordinator and corrective actions will be required. The impact of exceeding an action level on overall laboratory performance is given in Section 6.1.5. In accordance with Section 6.1.5.6, the site Project Manager shall have responsibility to ensure that appropriate corrective actions are taken when necessary.

\subsubsection{Accuracy of Quantitation}

6.1.2.1 Purpose. Analytical results for blind spikes of known concentration will be used to determine the accuracy with which a laboratory can quantitate the target analytes.

6.1.2.2 Criteria. The results reported for the target analytes present at concentrations greater than the PRQL should not deviate from the reference values by more than the values given in Table 1.

6.1.2.3 Evaluation Method. The reported analytical data are used to calculate the $\% \mathrm{R}$ for each of the target analytes as follows:

For individual PDP samples:

$$
\% R_{A}=\frac{C S_{A}}{R E F_{A}} \times 100
$$

where

$$
\begin{aligned}
& \% \mathrm{R}_{\mathrm{A}}=\text { percent recovery of compound } \mathrm{A} \text { in the PDP sample } \\
& \mathrm{CS}_{\mathrm{A}}=\begin{array}{l}
\text { measured concentration of compound } \mathrm{A} \text { from the laboratory's analysis of the } \\
\text { PDP sample }(\mathrm{mg} / \mathrm{kg})
\end{array} \\
& \mathrm{REF}_{\mathrm{A}}=\text { reference value of compound } \mathrm{A} \text { in the PDP sample }(\mathrm{mg} / \mathrm{kg}) .
\end{aligned}
$$

For matrix spike and matrix spike duplicates:

$$
\% R_{A}=\frac{C M S_{A}-C S_{A}}{M S C_{A}} \times 100
$$

where

$$
\begin{aligned}
& \% \mathrm{R}_{\mathrm{A}}=\text { percent recovery of compound } \mathrm{A} \text { in the matrix spike } \\
& \mathrm{CMS}_{\mathrm{A}}=\begin{array}{l}
\text { measured concentration of compound } \mathrm{A} \text { from the laboratory's analysis of the } \\
\text { matrix spike }(\mathrm{mg} / \mathrm{kg})
\end{array} \\
& \mathrm{CS}_{\mathrm{A}}=\begin{array}{l}
\text { measured concentration of compound } \mathrm{A} \text { from the laboratory's analysis of the } \\
\text { corresponding unspiked PDP sample }(\mathrm{mg} / \mathrm{kg})
\end{array}
\end{aligned}
$$


$\mathrm{MSC}_{\mathrm{A}}=$ concentration of compound $\mathrm{A}$ resulting from the addition of the matrix spike (mg/kg).

6.1.2.4 Actions. If all of the reporting laboratories report a specific analyte that falls outside the criteria of Section 6.1.2.2 in the same direction, then that data will be judged as inappropriate for use in the determination of performance for that round of the performance demonstration. This conclusion will be based on a comparison of the mean and standard deviation of the values reported by the participants to the reference value for the analyte using a single-tailed " $\mathrm{t}$ " test at the $95 \%$ confidence level. If there are insufficient participants to perform an adequate " $\mathrm{t}$ " test, data for individual compounds may still be judged inappropriate for use according to Section 6.1.5.5.

6.1.2.4.1 For any compound for which the $\% \mathrm{R}_{\mathrm{A}}$ is outside the range given in Table 1 in any of the blind spikes, the laboratory will be judged to have exceeded an action limit and unable to quantitate for compound A. Data for that compound will be identified as unacceptable by the Program Coordinator. The impact of exceeding an action level on overall laboratory performance is given in Section 6.1.5. In accordance with Section 6.1.5.6, the site Project Manager shall have responsibility to ensure that appropriate corrective actions are taken.

\subsubsection{Precision of Quantitation of Duplicates}

6.1.3.1 Purpose. Analytical results for duplicate blind spikes of known concentration will be used to determine the precision with which a laboratory can quantitate the target analytes.

6.1.3.2 Criteria. The difference between the results reported for the target analytes present at concentrations greater than the PRQL for duplicate determinations from different samples should not exceed the value given in Table 1 for the RPD.

6.1.3.3 Evaluation Method. The analytical results for all reported data are used to calculate the RPDs for each of the target analytes present at concentrations greater than the PRQL as follows:

$$
R P D_{A}=\frac{\left|C S_{A}-C D_{A}\right|}{\left[\frac{C S_{A}+C D_{A}}{2}\right]} \times 100
$$

where

$$
\begin{aligned}
& \mathrm{RPD}_{\mathrm{A}}=\begin{array}{l}
\text { relative percent difference between the measured values from two duplicate } \\
\text { samples }
\end{array} \\
& \mathrm{CS}_{\mathrm{A}}=\begin{array}{l}
\text { concentration of compound } \mathrm{A} \text { in determination from duplicate sample } 1 \\
(\mathrm{mg} / \mathrm{kg})
\end{array} \\
& \mathrm{CD}_{\mathrm{A}}=\begin{array}{l}
\text { concentration of compound } \mathrm{A} \text { in determination from duplicate sample } 2 \\
(\mathrm{mg} / \mathrm{kg})
\end{array}
\end{aligned}
$$


6.1.3.4 Actions. For any compound for which the $\mathrm{RPD}_{\mathrm{A}}$ exceeds the value given in Table 1 , the laboratory will be judged unable to quantitate reproducibly for that compound. Data for that compound will be identified as exceeding an action limit and unacceptable by the Program Coordinator. The impact of exceeding an action level on overall laboratory performance is given in Section 6.1.5. In accordance with Section 6.1.5.6, the site Project Manager shall have responsibility to ensure that appropriate corrective actions are taken.

\subsubsection{Precision of Replicate Determinations}

6.1.4.1 Purpose. Analytical results for replicate (i.e., triplicate or quadruplicate) analyses of blind spikes of known concentration will be used to determine the precision with which a laboratory can quantitate the target analytes.

6.1.4.2 Criteria. The sample standard deviation of the results reported for the target analytes for replicate analyses of the same blind samples should not exceed the value given in Table 1 for the RSD.

6.1.4.3 Evaluation Method. The analytical results for the replicate determinations for each sample are used to calculate the relative percent standard deviation for each of the target analytes as follows:

$$
\% R S D_{A}=\frac{s}{A C_{A}} \times 100
$$

where

$$
\begin{aligned}
\% \mathrm{RSD}_{\mathrm{A}} & =\text { relative standard deviation of the replicate determinations (percent) } \\
\mathbf{s} & =\text { standard deviation of the replicate determinations } \\
\mathrm{AC}_{\mathrm{A}} & =\text { average concentration of compound } \mathrm{A} \text { in replicate determinations }(\mathrm{mg} / \mathrm{kg}) .
\end{aligned}
$$

6.1.4.4 Actions. For any compound for which the $\% \mathrm{RSD}_{\mathrm{A}}$ exceeds the value given in Table 1, the laboratory will be judged unable to quantitate reproducibly for that compound. Data for that compound will be identified as unacceptable by the Program Coordinator. The impact of exceeding an action level on overall laboratory performance is given in Section 6.1.5. In accordance with Section 6.1.5.6, the site Project Manager shall have responsibility to ensure that appropriate corrective action measures are taken when necessary.

\subsubsection{Overall Performance}

6.1.5.1 Purpose. Individual laboratory performance on the set of PDP samples will be used to assess general problems that may affect the laboratory's ability to analyze for the compounds of interest. This conclusion could result in a holding period during which the laboratory would not analyze WIPP samples until the causes of the problems are identified, corrective action taken, and the efficacy of the corrective action demonstrated. 
6.1.5.2 Criteria. Laboratories must pass $90 \%$ of the accumulated performance criteria for target analytes (TAs) present in the blind spikes to be considered as qualified to perform VOC analysis on WIPP samples. The criterion is applied to the data from a single PDP distribution cycle.

6.1.5.3 Evaluation Methods. Table 1 lists the TAs. TAs are those compounds that have been identified in documentation and/or studies of TRU waste as:

- Critical to supporting ultimate granting of the no-migration variance from the land disposal restrictions

- Required for hazardous waste characterization supporting a Resource Conservation and Recovery Act (RCRA) permit.

6.1 5.3.1 The reported analyses of TAs in the PDP samples will be evaluated on a point scoring system. Results will be scored as follows:

a. For TAs present in the blind duplicate samples at concentrations above the PRQL, the laboratory will receive two (2) points for each detection of TAs that are known to be present and one (1) point for each evaluated \% R and RPD that meet the criteria of Sections 6.1.2.2 and 6.1.3.2, respectively. (Possible 7 points per compound).

b. For TAs present in the MS and MSD samples, but not used as one of the spiking compounds, the laboratory will receive two (2) points for each detection of TAs that are known to be present and one (1) point for each evaluated \% R and RSD that meet the criteria of Sections 6.1.2.2 and 6.1.4.2, respectively. (Possible 7 points per compound).

c. For TAs that are used as one of the spiking compounds in the MS and MSD samples, the laboratory will receive two (2) points for each detection of TAs that are known to be present and one (1) point for each evaluated \%R and RPD that meet the criteria of Sections 6.1.2.2 and 6.1.3.2, respectively. For TAs that are used as one of the spiking compounds in the MS and MSD samples, two (2) points will be subtracted for each failure to detect TAs that are known to be present and one (1) point will be subtracted for each evaluated \% R and RPD that fail to meet the criteria of Sections 6.1.2.2 and 6.1.3.2, respectively. (Possible +7 to -7 points per compound).

d. For TAs present in a single sample at concentration above the PRQL, the laboratory will receive two (2) points for each detection of TAs that are known to be present and one (1) point for each evaluated \% $\mathrm{R}$ that meets the criteria of Section 6.1.2.2. (Possible 3 points per compound).

e. For TAs present in any sample at concentrations less than the PRQL but greater than the PRDL, the laboratory will receive one (1) point for correctly identifying the TC. TAs in this range will not be scored for the \% $\mathrm{R}$ or, if present in duplicates, the RPD. 
f. Each laboratory will start with 39 points for each blank sample (1 point for each TC). From this total the laboratory will lose one (1) point for each TC for which the laboratory fails to meet the blank criteria of Section 6.1.1.2.

g. Each laboratory will lose one (1) point for each false positive (i.e., identification of a TC at or greater than the PRQL) in a sample in which the compound is known to be absent. This criterion does not apply to the blank sample that is evaluated as in (c), above.

h. Each laboratory will lose 0.1 points for each TIC that is known to be present but is not detected by the laboratory up to a maximum of 10 TICs.

i. Each laboratory will receive 0.1 points for each TIC that is known to be present and is detected by the laboratory up to a maximum of 10 TICs.

j. If an analyte is listed as optional for VOC or SVOC analysis in Table 1 and a laboratory elects to determine this analyte by the SVOC method only, the laboratory will automatically receive the appropriate number of points for VOC scoring that would have been awarded for correct analysis under sections a through e, above.

6.1.5.3.2 Example Calculation - Laboratory A receives six samples grouped as follows:

- Sample 1 is a blank.

- Samples 2 and 3 are blind duplicates containing 16 TAs at the same concentrations in each sample.

- Sample 4 contains 17 TAs at different concentrations than Samples 2 and 3: five of these TAs are less than the PRQL but greater than the PRDL.

- Samples 5 and 6 contain the same 17 TAs at the same concentrations as Sample 4 and are used as the MS and MSD. Five (5) of the TAs, all above the PRQL, are used for spiking. Data for the spiked compounds are used to calculate RPDs. Data for the unspiked compounds are used to calculate RSDs in conjunction with data from Sample 4.

The Laboratory can score a maximum of $286 \mathrm{TC}$ points, broken down as follows:

- $\quad$ Sample $1=39 \mathrm{TC}$ points $(39 \times 1)$

- $\quad$ Samples 2 and $3=112 \mathrm{TC}$ points $(16 \times 7)$

- $\quad$ Sample $4=41 \mathrm{TC}$ points $(12 \times 3+5 \times 1)$

- $\quad$ Sample 5 and $6=94$ TC points $(5 \times 7$ with RPDs, $7 \times 7$ with RSDs, and $5 \times 2)$. 
Laboratory TC Score $=100{ }^{\circ}\left(\mathrm{LP}_{\mathrm{TC}} / 286\right)$, where $\mathrm{LP}_{\mathrm{TC}}$ is the total number of $\mathrm{TC}$ points scored by the laboratory.

6.1.5.4 Special Scoring. On occasion, circumstances may dictate that special samples be distributed as part of the regular PDP distribution for the evaluation of specific analytical conditions or problems.

6.1.5.4.1 Specific samples may be distributed to test an individual analyte or a small group of analytes. Such circumstances may include incompatibility between the TAs and other constituents of the main sample distribution; inability to obtain a pure standard of a TAs; or uncertainties of the certification of a TAs in the main sample distribution, among others. Under these circumstances, the TAs will be identified to the laboratories and only the TAs will be scored. Laboratories will be neither credited nor penalized for analytical data submitted for compounds not identified as TAs present in that sample or for data submitted for compounds known to be absent in that sample.

6.1.5.5 Sample or Analyte Disqualification. If the preponderance of evidence from the participating laboratories supports a conclusion that the concentration of a specific analyte in a sample has not been certified accurately enough to demonstrate compliance with the criteria of the PDP, the Program Coordinator may judge the data for that analyte to be inappropriate for use in the evaluation of performance for that particular performance demonstration.

6.1.5.6 Actions. The site Project Manager shall have the responsibility of ensuring that appropriate corrective actions are implemented when a laboratory exceeds an action limit. The following are considered minimum mandatory measures that must be implemented when action limits are exceeded.

6.1.5.6.1 If a laboratory obtains a score less than $90 \%$ of the total possible TC points for TAs known to be present at concentrations in excess of the PRQL, the laboratory will be judged to have exceeded an action level.

6.1 5.6.2 Any laboratory that has exceeded an action level shall cease analytical operations for the analysis of WIPP samples. The laboratory may not begin analytical operations regarding the analysis of WIPP samples until the laboratory has completed the following actions:

- Investigated the cause(s) of the failure and taken corrective action

- Generated sufficient data to demonstrate that the same problems will not recur

- Demonstrated adequate performance, i.e., met the scoring criteria described in Section 6.1.4.2 on another set of PDP samples obtained through CAO and the Program Coordinator.

6.1.5.6.3 CAO may elect to grant conditional approval for a laboratory to perform waste characterization analyses for this program if such conditional approval will not compromise the overall quality of the data being generated for the program. Such a conditional approval may be granted if: 
- Laboratory's failure to meet criteria was limited to a very few compounds (possibly even a single compound)

- $\mathrm{CAO}$ has reason to believe that the error is systematic and likely to be correctable after appropriate corrective actions

- Limitations and conditions can be placed on the approval to guarantee that suspect data will not be used in the program.

6.1.5.6.4 CAO may waive the required demonstration of performance on a new set of PDP samples as a condition of laboratory approval if:

- Laboratory can prove that the cause of its failure to meet performance criteria was due purely to calculational errors

- Laboratory can demonstrate that appropriate control measures have been initiated to prevent recurrence of the errors.

6.1.5.6.5 If the laboratory elects not to qualify for a specific VOC/SVOC analyte(s) under 6.1.5.3.1.j, the approval of that laboratory for VOC analysis for waste characterization will specifically exclude the affected analytes from the approval.

\subsection{Total Analysis of Semivolatile Organic Compounds (SVOCs) - Table 2 Analytes}

SVOC analysis performance will be evaluated in the areas of performance on blanks, accuracy, precision, and correct detection and identification of TICs.

\subsubsection{Performance on Blanks}

6.2.1.1 Purpose. Analytical results for blanks are used to determine the presence of contamination problems and to quantify those problems if any exist.

6.2.1.2 Criteria. The criterion for blank performance is that none of the TAs should be present in the blank analyses at levels exceeding 50\% of the PRQL.

6.2.1.3 Evaluation Method. Acceptable blank performance is based on the data for all detected target analytes and the percent of their concentrations relative to the PRQL for that compound calculated as follows:

$$
R B T_{A}=\frac{C B_{A}}{P R Q L_{A}} \times 100
$$

where

$$
\mathrm{RBT}_{\mathrm{A}}=\text { amount of compound A calculated in blank as percent of the PRQL }
$$




$$
\begin{aligned}
& \mathrm{CB}_{\mathrm{A}}=\text { concentration of compound } \mathrm{A} \text { in blank }(\mathrm{mg} / \mathrm{kg}) \\
& \mathrm{PRQL}_{\mathrm{A}}=\text { required quantitation limit for compound } \mathrm{A}(\mathrm{mg} / \mathrm{kg}) .
\end{aligned}
$$

6.2.1.4 Actions. If all of the participating laboratories report a specific analyte to be present in the blank at levels exceeding $50 \%$ of the PRQL, the blank will be considered contaminated and the analyte data will be judged unusable and deleted from consideration in the performance criteria for that particular performance demonstration. This conclusion will be based on a comparison of the mean and standard deviation of the values reported by the participants to the contamination criteria (i.e., 50\% of the PRQL using a single-tailed " $t$ " test at the $95 \%$ confidence level). If there are insufficient participants to perform an adequate " $\mathrm{t}$ " test, data for individual compounds may still be judged inappropriate for use according to Section 6.2.5.5.

6.2.1.4.1 For any compound for which the $\mathrm{RBT}_{\mathrm{A}}$ exceeds $50 \%$, the laboratory will be judged to have exceeded an action limit for compound $\mathrm{A}$. Data for that compound will be identified as unacceptable by the Program Coordinator and corrective actions will be required. The impact of exceeding an action level on overall laboratory performance is given in Section 6.2.5. In accordance with Section 6.2.5.6, the site Project Manager shall have responsibility to ensure that appropriate corrective actions are taken when necessary.

\subsubsection{Accuracy of Quantitation}

6.2.2.1 Purpose. Analytical results for blind spikes of known concentration will be used to determine the accuracy with which a laboratory can quantitate the TAs.

6.2.2.2 Criteria. The results reported for the TAs should not deviate from the reference values by more than the values given in Table 2 .

6.2.2.3 Evaluation Method. The reported analytical data are used to calculate the \% $\mathrm{R}$ for each of the target analytes as follows:

For individual PDP samples:

$$
\% R_{A}=\frac{C S_{A}}{R E F_{A}} \times 100
$$

where

$$
\begin{aligned}
& \% \mathrm{R}_{\mathrm{A}}=\text { percent recovery of compound } \mathrm{A} \text { in the PDP sample } \\
& \mathrm{CS}_{\mathrm{A}}=\begin{array}{l}
\text { measured concentration of compound } \mathrm{A} \text { from the laboratory's analysis of the } \\
\text { PDP sample }(\mathrm{mg} / \mathrm{kg})
\end{array} \\
& \mathrm{REF}_{\mathrm{A}}=\text { reference value of compound } \mathrm{A} \text { in the PDP sample }(\mathrm{mg} / \mathrm{kg}) .
\end{aligned}
$$

For MS and MSDs: 


$$
\% R_{A}=\frac{C M S_{A}-C S_{A}}{M S C_{A}} \times 100
$$

where

$$
\begin{aligned}
& \% \mathrm{R}_{\mathrm{A}}=\text { percent recovery of compound } \mathrm{A} \text { in the matrix spike } \\
& \mathrm{CMS}_{\mathrm{A}}=\begin{array}{l}
\text { measured concentration of compound } \mathrm{A} \text { from the laboratory's analysis of the } \\
\text { matrix spike }(\mathrm{mg} / \mathrm{kg})
\end{array} \\
& \mathrm{CS}_{\mathrm{A}}=\begin{array}{l}
\text { measured concentration of compound } \mathrm{A} \text { from the laboratory's analysis of the } \\
\text { corresponding unspiked PDP sample }(\mathrm{mg} / \mathrm{kg})
\end{array} \\
& \mathrm{MSC}_{\mathrm{A}}=\begin{array}{l}
\text { concentration of compound } \mathrm{A} \text { resulting from the addition of the matrix spike } \\
(\mathrm{mg} / \mathrm{kg}) .
\end{array}
\end{aligned}
$$

6.2.2.4 Actions. If all of the reporting laboratories report a specific analyte that falls outside the criteria of Section 6.2.2.2 in the same direction, then that data will be judged as inappropriate for use in the determination of performance for that round of the performance demonstration. This conclusion will be based on a comparison of the mean and standard deviation of the values reported by the participants to the reference value for the analyte using a single-tailed " $t$ " test at the $95 \%$ confidence level. If there are insufficient participants to perform an adequate " $\mathrm{t}$ " test, data for individual compounds may still be judged inappropriate for use according to Section 6.2.5.5.

6.2.2.4.1 For any compound for which the $\% \mathrm{R}_{\mathrm{A}}$ is outside the range given in Table 2 in any of the blind spikes, the laboratory will be judged unable to quantitate for compound $\mathrm{A}$. Data for that compound will be identified as unacceptable by the Program Coordinator. The impact of exceeding an action level on overall laboratory performance is given in Section 6.2.5. In accordance with Section 6.2.5.6, the site Project Manager shall have responsibility to ensure that appropriate corrective actions are taken when necessary.

\subsubsection{Precision of Quantitation of Duplicates}

6.2.3.1 Purpose. Analytical results for duplicate blind spikes of known concentration will be used to determine the precision with which a laboratory can quantitate the TAs.

6.2.3.2 Criteria. The difference between the results reported for the TAs for duplicate determinations from different samples should not exceed the value given in Table 2 for the RPD.

6.2.3.3 Evaluation Method. The analytical results for all reported data are used to calculate the RPDs for each of the target analytes as follows: 


$$
R P D_{A}=\frac{\left|C S_{A}-C D_{A}\right|}{\left[\frac{C S_{A}+C D_{A}}{2}\right]} \times 100
$$

where

$$
\begin{aligned}
& \mathrm{RPD}_{\mathrm{A}}=\begin{array}{l}
\text { relative percent difference between the measured values from two duplicate } \\
\text { samples }
\end{array} \\
& \mathrm{CS}_{\mathrm{A}}=\begin{array}{l}
\text { concentration of compound } \mathrm{A} \text { in determination from duplicate Sample } 1 \\
(\mathrm{mg} / \mathrm{kg})
\end{array} \\
& \mathrm{CD}_{\mathrm{A}}=\begin{array}{l}
\text { concentration of compound } \mathrm{A} \text { in determination from duplicate Sample } 2 \\
(\mathrm{mg} / \mathrm{kg}) .
\end{array}
\end{aligned}
$$

6.2.3.4 Actions. For any compound for which the RPDA exceeds the value given in Table 2, the laboratory will be judged unable to quantitate reproducibly for that compound. Data for that compound will be identified as unacceptable by the Program Coordinator. The impact of exceeding an action level on overall laboratory performance is given in Section 6.2.5. In accordance with Section 6.2.5.6, the site Project Manager shall have responsibility to ensure that appropriate corrective actions are taken when necessary.

\subsubsection{Precision of Replicate Determinations}

6.2.4.1 Purpose. Analytical results for replicate (i.e., triplicate or quadruplicate) analyses of blind spikes of known concentration will be used to determine the precision with which a laboratory can quantitate the TAs.

6.2.4.2 Criteria. The sample standard deviation of the results reported for the TAs for replicate analyses of the same blind samples should not exceed the value given in Table 2 for the RSD.

6.2.4.3 Evaluation Method. The analytical results for the replicate determinations for each sample are used to calculate the relative percent standard deviation for each of the TAs as follows:

$$
\% R S D_{A}=\frac{s}{A C_{A}} \times 100
$$

where

$$
\begin{array}{ll}
\% \mathrm{RSD}_{\mathrm{A}} & =\text { relative standard deviation of the replicate determinations (percent) } \\
\mathrm{s} & =\text { standard deviation of the replicate determinations } \\
\mathrm{AC}_{\mathrm{A}} & =\text { average concentration of compound } \mathrm{A} \text { in replicate determinations }(\mathrm{mg} / \mathrm{kg}) .
\end{array}
$$


6.2.4.4 Actions. For any compound for which the $\% \mathrm{RSD}_{\mathrm{A}}$ exceeds the value given in Table 2, the laboratory will be judged unable to quantitate reproducibly for that compound. Data for that compound will be identified as unacceptable by the Program Coordinator. The impact of exceeding an action level on overall laboratory performance is given in Section 6.2.5. In accordance with Section 6.2.5.6, the site Project Manager shall have responsibility to ensure that appropriate corrective action measures are taken when necessary.

\subsubsection{Overall Performance}

6.2.5.1 Purpose. Individual laboratory performance on the set of PDP samples will be used to assess general problems that may affect the laboratory's ability to analyze the compounds of interest. This conclusion could result in a holding period during which the laboratory would not analyze WIPP samples until the causes of the problems are identified, corrective action taken, and the efficacy of the corrective action demonstrated.

6.2.5.2 Criteria. Laboratories must pass $90 \%$ of the accumulated performance criteria for TAs present in the blind spikes to be considered as qualified to perform SVOC analysis on WIPP samples. Criteria are applied to the data from a single PDP distribution cycle.

6.2.5.3 Evaluation Methods. Table 2 lists the TAs. TAs are those compounds that have been identified in documentation and/or studies of TRU waste as:

- Critical to supporting ultimate granting of the no-migration variance from the land disposal restrictions

- $\quad$ Required for hazardous waste characterization supporting a RCRA permit.

6.2.5.3.1 The reported analyses of TAs in the PDP samples will be evaluated on a point scoring system. Results will be scored as follows:

a. For TAs present in the duplicate samples at concentrations above the PRQL, the laboratory will receive two (2) points for each detection of TAs that are known to be present and one (1) point for each evaluated \% R and RPD that meet the criteria of Sections 6.2.2.2 and 6.2.3.2, respectively. (Possible 7 points per compound).

b. For TAs present in the MS and MSD samples, but not used as one of the spiking compounds, the laboratory will receive two (2) points for each detection of TAs that are known to be present and one (1) point for each evaluated \% R and RSD that meet the criteria of Sections 6.2.2.2 and 6.2.4.2, respectively. (Possible 7 points per compound).

c. For TAs that are used as one of the spiking compounds in the MS and MSD samples, the laboratory will receive two (2) points for each detection of TAs that are known to be present and one (1) point for each evaluated $\% \mathrm{R}$ and RPD that meet the criteria of Sections 6.2.2.2 and 6.2.3.2, respectively. For TAs that are used as one of the spiking compounds in the MS and MSD samples, two (2) points will be subtracted for each failure to detect TAs that are known to be present and one (1) point will be subtracted 
for each evaluated \% $\mathrm{R}$ and RPD that fails to meet the criteria of Sections 6.2.2.2 and 6.2.3.2, respectively. (Possible +7 to -7 points per compound).

d. For TAs present in a single sample at concentrations at or above the PRQL, the laboratory will receive two (2) points for each detection of TAs that are known to be present and one (1) point for each evaluated $\% \mathrm{R}$ that meets the criteria of Section 6.2.2.2. (Possible 3 points per compound).

e. For TAs present in any sample at concentrations less than the PRQL but greater than the PRDL, the laboratory will receive one (1) point for correctly identifying the TC. TAs in this range will not be scored for the \% $\mathrm{R}$ or, if present in duplicates, the RPD.

f. Each laboratory will start with ten (10) points for each blank sample (1 point for each TC). From this total the laboratory will lose one (1) point for each TC for which the laboratory fails to meet the blank criteria of Section 6.2.1.2. (For Waste Matrix Code 3220 , organic sludges, the total number of TAs will be increased to 17 to accommodate the required $\mathrm{PCB}$ analysis.)

g. Each laboratory will lose one (1) point for each false positive (i.e., identification of a TC at or greater than the PRQL) in a sample in which the compound is known to be absent. This criterion does not apply to the blank sample that is evaluated as in (c), above.

h. Each laboratory will lose 0.1 points for each TIC that is known to be present but is not detected by the laboratory up to a maximum of 10 TICs.

i. Each laboratory will receive 0.1 points for each TIC that is known to be present and is detected by the laboratory up to a maximum of 10 TICs.

j. If an analyte is listed as optional for VOC or SVOC analysis in Table 1 and a laboratory elects to determine this analyte by the VOC method only, the laboratory will automatically receive the appropriate number of points for SVOC scoring that would have been awarded for correct analysis under sections a through $e$, above.

follows:

6.2.5.3.2 Example Calculation - Laboratory A receives six samples grouped as

- Sample 1 is a blank

- Samples 2 and 3 are blind duplicates containing six TAs at the same concentrations in each sample

- Sample 4 contains seven TAs at different concentrations than Samples 2 and 3; two of these TAs are less than the PRQL but greater than the PRDL.

- Samples 5 and 6 contain the same seven TAs at the same concentrations as Sample 4 and are used as the MS and MSD. Three (3) of the TAs, all above the PRQL, are 
used for spiking. Data for the spiked compounds are used to calculate RPDs. Data for the unspiked compounds are used to calculate RSDs in conjunction with data from Sample 4.

The laboratory can score a maximum of $108 \mathrm{TC}$ points, broken down as follows:

- Sample $1=10 \mathrm{TC}$ points $(10 \times 1)$

- $\quad$ Samples 2 and $3=42$ TC points $(6 \times 7)$

- $\quad$ Sample $4=17 \mathrm{TC}$ points $(5 \times 3+2 \times 1)$

- Samples 5 and $6=39$ TC points $(3 \times 7$ with RPDs, $2 \times 7$ with RSDs, and $2 \times 2$ ).

Laboratory $\mathrm{TC}$ Score $=100^{*}\left(\mathrm{LP}_{\mathrm{TC}} / 108\right)$, where $\mathrm{LP}_{\mathrm{TC}}$ is the total number of TC points scored by the laboratory.

6.2.5.4 Special Scoring. On occasion, circumstances may dictate that special samples be distributed as part of the regular PDP distribution for the evaluation of specific analytical conditions or problems.

6.2.5.4.1 Specific samples may be distributed to test an individual analyte or a small group of analytes. Such circumstances may include incompatibility between the TAs and other constituents of the main sample distribution; inability to obtain a pure standard of a TAs; or uncertainties of the certification of a TAs in the main sample distribution, among others. Under these circumstances, the TAs will be identified to the laboratories and only the TAs will be scored. Laboratories will be neither credited nor penalized for analytical data submitted for compounds not identified as TAs present in that sample or for data submitted for compounds known to be absent in that sample.

6.2.5.5 Sample or Analyte Disqualification. If the preponderance of evidence from the participating laboratories supports a conclusion that the concentration of a specific analyte in a sample has not been certified accurately enough to demonstrate compliance with the criteria of the PDP, the Program Coordinator may judge the data for that analyte to be inappropriate for use in the evaluation of performance for that particular performance demonstration.

6.2.5.6 Actions. The site Project Manager shall have the responsibility of ensuring that appropriate corrective actions are implemented when a laboratory exceeds an action limit. The following are considered minimum mandatory measures that must be implemented when action limits are exceeded.

6.2.5.6.1 If a laboratory obtains a score less than $90 \%$ of the total possible TC points for TAs known to be present at concentrations in excess of the PRQL, the laboratory will be judged to have exceeded an action level. 
6.2.5.6.2 Any laboratory that has exceeded an action level shall cease analytical operations for the analysis of WIPP samples. The laboratory may not begin analytical operations regarding the analysis of WIPP samples until the laboratory has completed the following actions:

- Investigated the cause(s) of the failure and taken corrective action

- Generated sufficient data to demonstrate that the same problems will not recur

- Demonstrated adequate performance, i.e., met the scoring criteria described in Section 6.2.4.2 on another set of PDP samples obtained through CAO and the Program Coordinator.

6.2.5.6.3 CAO may elect to grant conditional approval for a laboratory to perform waste characterization analyses for this program if such conditional approval will not compromise the overall quality of the data being generated for the program. Such a conditional approval may be granted if:

- Laboratory's failure to meet criteria was limited to a very few compounds (possibly even a single compound)

- CAO has reason to believe that the error is systematic and likely to be correctable after appropriate corrective actions

- Limitations and conditions can be placed on the approval to guarantee that suspect data will not be used in the program.

6.2.5.6.4 $\mathrm{CAO}$ may waive the required demonstration of performance on a new set of PDP samples as a condition of laboratory approval if:

- Laboratory can prove that the cause of its failure to meet performance criteria was due purely to calculational errors

- Laboratory can demonstrate that appropriate control measures have been initiated to prevent recurrence of the errors.

6.2.5.6.5 If the laboratory elects not to qualify for a specific VOC/SVOC analyte(s) under 6.2.5.3.1.j, the approval of that laboratory for SVOC analysis for waste characterization will specifically exclude the affected analytes from the approval.

\subsection{Analysis of Total Metals - Table 3 Analytes}

Metals analysis performance will be evaluated in the areas of performance on blanks, accuracy, and precision. 


\subsubsection{Performance on Blanks}

6.3.1.1 Purpose. Analytical results for blanks are used to determine the presence of contamination or interference problems and to quantify those problems if any exist.

6.3.1.2 Criteria. The criterion for blank performance is that none of the TAs should be present in the blank analyses at levels exceeding 50\% of the PRQL.

6.3.1.3 Evaluation Method. Acceptable blank performance is based on the data for all detected TAs and the percent of their concentrations relative to the PRQL for that analyte calculated as follows:

$$
R B T_{A}=\frac{C B_{A}}{P R Q L_{A}} \times 100
$$

where

$$
\begin{aligned}
& \mathrm{RBT}_{\mathrm{A}}=\text { amount of analyte } \mathrm{A} \text { calculated in blank as percent of the PRQL } \\
& \mathrm{CB}_{\mathrm{A}}=\text { concentration of analyte } \mathrm{A} \text { in blank }(\mathrm{mg} / \mathrm{kg}) \\
& \mathrm{PRQL}_{\mathrm{A}}=\text { required quantitation limit for analyte } \mathrm{A}(\mathrm{mg} / \mathrm{kg}) .
\end{aligned}
$$

6.3.1.4 Actions. If all of the participating laboratories report a specific analyte to be present in the blank at levels exceeding $50 \%$ of the PRQL, the blank will be considered contaminated and the analyte data will be judged unusable and deleted from consideration in the performance criteria for that particular performance demonstration. This conclusion will be based on a comparison of the mean and standard deviation of the values reported by the participants to the contamination criteria (i.e., 50\% of the PRQL) using a single-tailed " $\mathrm{t}$ " test at the $95 \%$ confidence level. If there are insufficient participants to perform an adequate " $t$ " test, data for individual compounds may still be judged inappropriate for use according to Section 6.3.4.5.

6.3.1.4.1 For any analyte for which the $\mathrm{RBT}_{\mathrm{A}}$ exceeds $50 \%$, the laboratory will be judged to have exceeded an action limit for analyte $\mathrm{A}$. Data for that analyte will be identified as unacceptable by the Program Coordinator and corrective actions will be required. The impact of exceeding an action level on overall laboratory performance is given in Section 6.3.4. In accordance with Section 6.3.4.6, the site Project Manager shall have responsibility to ensure that appropriate corrective actions are taken when necessary.

\subsubsection{Accuracy of Quantitation}

6.3.2.1 Purpose. Analytical results for blind spikes of known concentration will be used to determine the accuracy with which a laboratory can quantitate the TAs.

6.3.2.2 Criteria. The results reported for those TAs present at concentrations greater than the PRQL should not deviate from the reference values by more than the values given in Table 3 . 
6.3.2.3 Evaluation Method. The reported analytical data are used to calculate the \% R for each of the TAs as follows:

For individual PDP samples:

$$
\% R_{A}=\frac{C S_{A}}{R E F_{A}} \times 100
$$

where

$$
\begin{aligned}
& \% \mathrm{R}_{\mathrm{A}}=\text { percent recovery of analyte } \mathrm{A} \text { in the PDP sample } \\
& \mathrm{CS}_{\mathrm{A}}=\begin{array}{l}
\text { measured concentration of analyte } \mathrm{A} \text { from the laboratory's analysis of the } \\
\text { PDP sample }(\mathrm{mg} / \mathrm{kg})
\end{array}
\end{aligned}
$$

$\mathrm{REF}_{\mathrm{A}}=$ reference value of analyte $\mathrm{A}$ in the PDP sample (mg/kg).

For MS and MSDs:

$$
\% R_{A}=\frac{C M S_{A}-C S_{A}}{M S C_{A}} \times 100
$$

where

$$
\begin{aligned}
& \% \mathrm{R}_{\mathrm{A}}=\text { percent recovery of analyte } \mathrm{A} \text { in the matrix spike } \\
& \mathrm{CMS}_{\mathrm{A}}=\begin{array}{l}
\text { measured concentration of analyte } \mathrm{A} \text { from the laboratory's analysis of the } \\
\text { matrix spike }(\mathrm{mg} / \mathrm{kg})
\end{array} \\
& \mathrm{CS}_{\mathrm{A}}=\begin{array}{l}
\text { measured concentration of analyte } \mathrm{A} \text { from the laboratory's analysis of the } \\
\text { corresponding unspiked PDP sample }(\mathrm{mg} / \mathrm{kg})
\end{array} \\
& \mathrm{MSC}_{\mathrm{A}}=\text { concentration of analyte A resulting from the addition of the } \mathrm{MS}(\mathrm{mg} / \mathrm{kg}) .
\end{aligned}
$$

6.3.2.4 Actions. If all of the reporting laboratories report a specific analyte that falls outside the criteria of Section 6.3.2.2 in the same direction, then that data will be judged as inappropriate for use in the determination of performance for that round of performance demonstration. This conclusion will be based on a comparison of the mean and standard deviation of the values reported by the participants to the reference value for the analyte using a single-tailed " $t$ " test at the $95 \%$ confidence level. If there are insufficient participants to perform an adequate test, data for individual compounds may still be judged inappropriate for use according to Section 6.3.4.5.

6.3.2.4.1 For any analyte for which the $\% \mathrm{R}_{\mathrm{A}}$ is outside the range given in Table 3 in any of the blind spikes, the laboratory will be judged unable to quantitate for analyte A. Data for that analyte will be identified as unacceptable by the Program Coordinator. The impact of exceeding an action level on overall laboratory performance is given in Section 6.3.4. In 
accordance with Section 6.3.4.6, the site Project Manager shall have responsibility to ensure that appropriate corrective actions are taken when necessary.

\subsubsection{Precision of Quantitation of Duplicates}

6.3.3.1 Purpose. Analytical results for duplicate blind spikes of known concentration will be used to determine the precision with which a laboratory can quantitate the TAs.

6.3.3.2 Criteria. The difference between the results reported for the TAs for duplicate determinations from different samples should not exceed the value given in Table 3 for the RPD.

6.3.3.3 Evaluation Method. The analytical results for all reported data are used to calculate the RPDs for each of the TAs present at concentrations greater than the PRQL as follows:

$$
R P D_{A}=\frac{\left|C S_{A}-C D_{A}\right|}{\left[\frac{C S_{A}+C D_{A}}{2}\right]} \times 100
$$

where

$$
\begin{aligned}
& \mathrm{RPD}_{\mathrm{A}}= \begin{array}{l}
\text { relative percent difference between the measured values from two duplicate } \\
\text { samples }
\end{array} \\
& \mathrm{CS}_{\mathrm{A}}= \begin{array}{l}
\text { concentration of analyte } \mathrm{A} \text { in determination from duplicate Sample } 1 \\
(\mathrm{mg} / \mathrm{kg})
\end{array} \\
& \mathrm{CD}_{\mathrm{A}}=\begin{array}{l}
\text { concentration of analyte } \mathrm{A} \text { in determination from duplicate Sample } 2 \\
(\mathrm{mg} / \mathrm{kg}) .
\end{array}
\end{aligned}
$$

6.3.3.4 Actions. For any analyte for which the $\mathrm{RPD}_{\mathrm{A}}$ exceeds the value given in Table 3, the laboratory will be judged unable to quantitate reproducibly for that analyte. Data for that analyte will be identified as unacceptable by the Program Coordinator. The impact of exceeding an action level on overall laboratory performance is given in Section 6.3.4. In accordance with Section 6.3.4.6, the site Project Manager shall have responsibility to ensure that appropriate corrective actions are taken when necessary.

\subsubsection{Overall Performance}

6.3.4.1 Purpose. Individual laboratory performance on the set of PDP samples will be used to assess general problems that may affect the laboratory's ability to analyze the analytes (TAs) of interest. This conclusion could result in a holding period during which the laboratory would not analyze WIPP samples until the causes of the problems are identified, corrective action taken, and the efficacy of the corrective action demonstrated. 
6.3.4.2 Criteria. Laboratories must pass $90 \%$ of the accumulated performance criteria for TAs present in the blind spikes above the PRQL to be considered as qualified to perform metals analysis on WIPP samples. Criteria are applied to the data from a single PDP distribution cycle.

6.3.4.3 Evaluation Methods. Table 3 lists the TAs. TAs are those analytes that have been identified in documentation and/or studies of TRU waste as:

- Critical to supporting ultimate granting of the no-migration variance from the land disposal restrictions

- $\quad$ Required for hazardous waste characterization supporting a RCRA permit.

6.3.4.3.1 The reported analyses of TAs in the PDP samples will be evaluated on a point scoring system. Results will be scored as follows:

a. For TAs present in the duplicate samples at concentrations above the PRQL, the laboratory will receive two (2) points for each detection of TAs that are known to be present and one (1) point for each evaluated \% $\mathrm{R}$ and RPD that meet the criteria of Sections 6.3.2.2 and 6.3.3.2, respectively. (Possible 7 points per analyte).

b. For TAs that are used as one of the spiking analytes in the MS and MSD samples, the laboratory will receive two (2) points for each detection of TAs that are known to be present and one (1) point for each evaluated \%R and RPD that meet the criteria of Sections 6.3.2.2 and 6.3.3.2, respectively. For TAs that are used as one of the spiking analytes in the MS and MSD samples, two (2) points will be subtracted for each failure to detect TAs that are known to be present and one (1) point will be subtracted for each evaluated \% R and RPD that fails to meet the criteria of Sections 6.3.2.2 and 6.3.3.2, respectively. (Possible +7 to -7 points per analyte).

c. For TAs present in a single sample at concentrations above the PRQL, the laboratory will receive two (2) points for each detection of TAs that are known to be present and one (1) point for each evaluated \% $\mathrm{R}$ that meets the criteria of Section 6.3.2.2. (Possible 3 points per analyte).

d. For TAs present in any sample at concentrations less than the PRQL but greater than the PRDL, the laboratory will receive one (1) point for correctly identifying the TA TAs in this range will not be scored for the \% $\mathrm{R}$ or, if present in duplicates, the RPD.

e. Each laboratory will start with 14 points for each blank sample (1 point for each TA). From this total the laboratory will lose one (1) point for each TA for which the laboratory fails to meet the blank criteria of Section 6.3.1.2.

f. Each laboratory will lose one (1) point for each false positive (i.e., identification of a TA at or greater than the PRQL) in a sample in which the analyte is known to be absent. This criterion does not apply to the blank sample that is evaluated as in (c), above. 
follows:

6.3.4.3.2 Example Calculation - Laboratory A receives four samples grouped as

- Sample 1 is a blank

- Samples 2 and 3 are blind duplicates containing 9 TAs at the same concentrations in each sample all above the PRQL

- Sample 4 contains 10 TAs at different concentrations than Samples 2 and 3; two of these TAs are less than the PRQL but greater than PRDL

- One sample will be designated for use as the MS and MSD and will contain the same 10 TAs at the same concentrations as Sample 4. All 14 of the possible TAs are used for spiking at the PRQL.

The Laboratory can score a maximum of $185 \mathrm{TA}$ points, broken down as follows:

- $\quad$ Sample $1=14$ TA points $(14 \times 1)$

- Samples 2 and $3=63$ TA points $(9 \times 7)$

- Sample $4=26 \mathrm{TA}$ points $(8 \times 3+2 \times 1)$

- $\quad$ Sample $5=98 \mathrm{TA}$ points $(14 \times 7)$.

Laboratory TA Score $=100^{*}\left(\mathrm{LP}_{\mathrm{TA}} / 201\right)$, where $\mathrm{LP}_{\mathrm{TA}}$ is the total number of TA points scored by the laboratory.

6.3.4.4 Special Scoring. On occasion, circumstances may dictate that special samples be distributed as part of the regular PDP distribution for the evaluation of specific analytical conditions or problems.

6.3.4.4.1 Specific samples may be distributed to test an individual analyte or a small group of analytes. Such circumstances may include incompatibility between the TAs and other constituents of the main sample distribution; inability to obtain a pure standard of a TAs; or uncertainties of the certification of a TAs in the main sample distribution, among others. Under these circumstances, the TAs will be identified to the laboratories and only the TAs will be scored. Laboratories will be neither credited nor penalized for analytical data submitted for analytes not identified as TAs present in that sample or for data submitted for analytes known to be absent in that sample.

6.3.4.5 Sample or Analyte Disqualification. If the preponderance of evidence from the participating laboratories supports a conclusion that the concentration of a specific analyte in a sample has not been certified accurately enough to demonstrate compliance with the criteria of the PDP, the Program Coordinator may judge the data for that analyte to be inappropriate for use in the evaluation of performance for that particular performance demonstration. 
6.3.4.6 Actions. The site Project Manager shall have the responsibility of ensuring that appropriate corrective actions are implemented when a laboratory exceeds an action limit. The following are considered minimum mandatory measures that must be implemented when action limits are exceeded.

6.3.4.6.1 If a laboratory obtains a score less than $90 \%$ of the total possible TA points for TAs known to be present at concentrations in excess of the PRQL, the laboratory will be judged to have exceeded an action level.

6.3.4.6.2 Any laboratory that has exceeded an action level shall cease analytical operations for the analysis of WIPP samples. The laboratory may not begin analytical operations regarding the analysis of WIPP samples until the laboratory has completed the following actions:

- Investigated the cause(s) of the failure and taken corrective action

- Generated sufficient data to demonstrate that the same problems will not recur

- Demonstrated adequate performance, i.e., met the scoring criteria described in Section 6.3.4.2 on another set of PDP samples obtained through CAO and the Program Coordinator.

6.3.4.6.3 CAO may elect to grant conditional approval for a laboratory to perform waste characterization analyses for this program if such conditional approval will not compromise the overall quality of the data being generated for the program. Such a conditional approval may be granted if:

- Laboratory's failure to meet criteria was limited to a very few analytes (possibly even a single analyte)

- CAO has reason to believe that the error is systematic and likely to be correctable after appropriate corrective actions

- Limitations and conditions can be placed on the approval to guarantee that suspect data will not be used in the program.

6.3.4.6.4 CAO may waive the required demonstration of performance on a new set of PDP samples as a condition of laboratory approval if:

- Laboratory can prove that the cause of its failure to meet performance criteria was due purely to calculational errors

- Laboratory can demonstrate that appropriate control measures have been initiated to prevent recurrence of the errors. 


\section{REPORTING OF PERFORMANCE DATA}

\subsection{Summary of Data}

The Program Coordinator shall review and evaluate the results, compile them into a master summary, and deliver this summary to DOE-CAO within 3 weeks postreceipt of the last laboratory data set or within 6 weeks of the last VTSR, whichever occurs last. The report due date will be extended by a time equivalent to any extension granted by CAO under Section 5.2.4. The report summary shall include the values reported by the laboratories, the reference target analyte values, the acceptance ranges per target analyte, and the pass/fail status of each individual laboratory.

DOE-CAO, in conjunction with the Program Coordinator, will evaluate individual laboratory performance and approve individual laboratories for participation in the WIPP waste characterization program. Depending on the results of the PDP, the generator site Project Manager(s) shall have the responsibility of ensuring that appropriate corrective actions are taken. The semiannual QA reports (Section 2.2 of the TRU Waste Characterization QAPP for the WIPP) must assess the impact of corrective actions taken.

\subsection{Distribution of Reports}

Copies of the summary report shall be distributed to each of the DOE Operations Offices involved, to each of the participating laboratories, to all individuals involved in the administration or conduct of the program, and to such other individuals and organizations as CAO shall deem appropriate. The identification of individual laboratories shall be coded in copies of the master summary distributed by $\mathrm{CAO}$. CAO shall also provide written notification to the DOE-Operations Offices regarding the adequacy and approval status of their participating laboratories.

\subsection{Backup PDP Samples}

A backup set of blind audit samples can be prepared by the SPC approximately 4 weeks after laboratories are notified of their status. Laboratories that do not pass on the initial set of blind audit samples may request to have these samples prepared and sent to their facility. Requests must be submitted in writing to $\mathrm{CAO}$ and be accompanied by a report stating the reasons for the failures and any corresponding corrective actions that were taken. The schedule of distribution, analysis, scoring, and approval/disapproval actions by $\mathrm{CAO}$ will be negotiated for each supplemental distribution. The schedule will be based on discussions with the potential participants and a review of impacts on the overall WIPP schedule. Timing of and selection of laboratories for participation in supplemental distributions will be entirely at the discretion of CAO. Primary consideration will be given to preventing adverse impacts on WIPP waste characterization and compliance schedules. 


\subsection{Laboratory Status}

Once CAO has made a determination of measurement facility status with respect to analyses that are required by the WIPP to demonstrate compliance with regulatory requirements, such status shall remain in effect until a new determination is made by CAO. Laboratories obtaining approved status through a supplemental distribution cycle must participate in the next regular distribution cycle to maintain their approved status. 


\section{REFERENCES}

1. DOE, 1994a, Transuranic Waste Characterization Quality Assurance Program Plan, DOE/CAO 94-1010, Current Revision, Carlsbad, New Mexico, Carlsbad Area Office, U.S. Department of Energy.

2. DOE, 1994b, Performance Demonstration Program Plan for Nondestructive Assay for the TRU Waste Characterization Program, DOE/CAO 94-1045, Revision 0, December 1994, Carlsbad, New Mexico, Carlsbad Area Office, U.S. Department of Energy.

3. DOE, 1994c, Transuranic Waste Characterization Program Sampling and Analysis Methods Manual, DOE/WIPP 91-043, Current Revision, Carlsbad, New Mexico, Carlsbad Area Office, U.S. Department of Energy.

4. DOE, 1995a, Performance Demonstration Program Plan for the Analysis of Simulated Headspace Gases for the TRU Waste Characterization Program, DOE/CAO 95-1076, Revision 0, April 1995, Carlsbad, New Mexico, Carlsbad Area Office, U.S. Department of Energy. 


\section{Appendix A}

\section{Sample Chain of Custody Form}




\section{WIPP EXPERIMENTAL WASTE CHARACTERIZATION PROGRAM LABORATORY PERFORMANCE DEMONSTRATION Delivery/Chain-of-Custody Record}

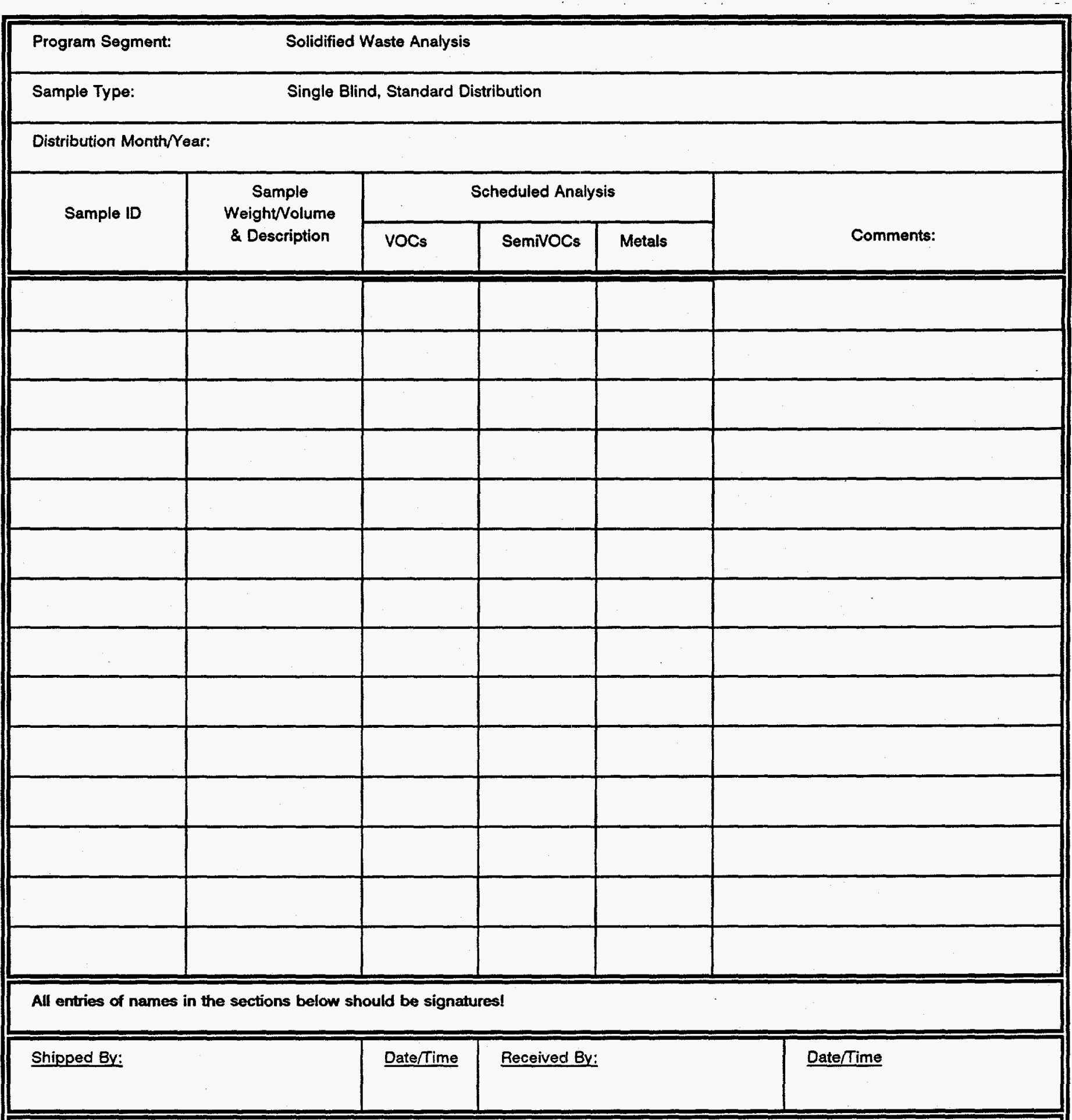

After completion to this point, return attached copy to Shipper! 


\begin{tabular}{|c|c|c|c|}
\hline Program Segment: & \multicolumn{3}{|l|}{ Solidified Waste Analysis } \\
\hline Sample Type: & \multicolumn{3}{|c|}{ Single Blind, Standard Distribution } \\
\hline \multicolumn{4}{|c|}{ Distribution Month/Year: } \\
\hline Relinquished By: & Date/Time & Received By: & Date/Time \\
\hline Relinquished By: & Date/Time & Received By: & Date/Time \\
\hline Relinquished By: & Date/Time & Received By: & Date/Time \\
\hline Relinquished By: & Date/Time & Received By: & Date/Time \\
\hline Relinquished By: & DaterTime & Received By: & Date/Time \\
\hline Relinquished By: & Date/Time & Received By: & Date/Time \\
\hline Final Disposition By: & & Disposition: & \\
\hline
\end{tabular}




\section{Appendix B}

\section{Sample Data Reporting Form}


PERFORMANCE DEMONSTRATION PROGRAM REPORT FORM SIMULATED SOLIDIFIED WASTE ANALYSIS

\begin{tabular}{|c|c|c|c|c|c|c|}
\hline Laboratory Name : & & \multirow{2}{*}{\multicolumn{2}{|c|}{$\frac{\text { Report Page }}{\text { Laboratory Sample ID : }}$}} & \multicolumn{2}{|l|}{ Pages } & \\
\hline \multicolumn{2}{|l|}{ PDP Distribution (Mo/Yr) : } & & & & & \\
\hline Sample No.: & & \multicolumn{5}{|c|}{ Program Component: } \\
\hline \multirow{2}{*}{ Analyte } & \multirow[b]{2}{*}{$\begin{array}{l}\text { Result } \\
(\mathrm{mg} / \mathrm{kg})\end{array}$} & \multirow[b]{2}{*}{ Flag } & \multirow[b]{2}{*}{$\begin{array}{c}\text { Method } \\
\text { Identification }\end{array}$} & \multicolumn{2}{|c|}{ Analysis } & \multirow{2}{*}{ Comment } \\
\hline & & & & Date & Time & \\
\hline & & & & & & \\
\hline & & & & & & \\
\hline & & & & & & \\
\hline & & & & & & \\
\hline & & & & & & \\
\hline & & & & & & \\
\hline & & & & & & \\
\hline & & & & & & \\
\hline & & & & & & \\
\hline & & & & & & \\
\hline & & & & & & \\
\hline & & & & & & \\
\hline & & & & & & \\
\hline & & & & & & \\
\hline & & & & & & \\
\hline & & & & & & \\
\hline & & & & & & \\
\hline & & & & & & \\
\hline & & & & & & \\
\hline & & & & & & \\
\hline & & & & & & \\
\hline
\end{tabular}




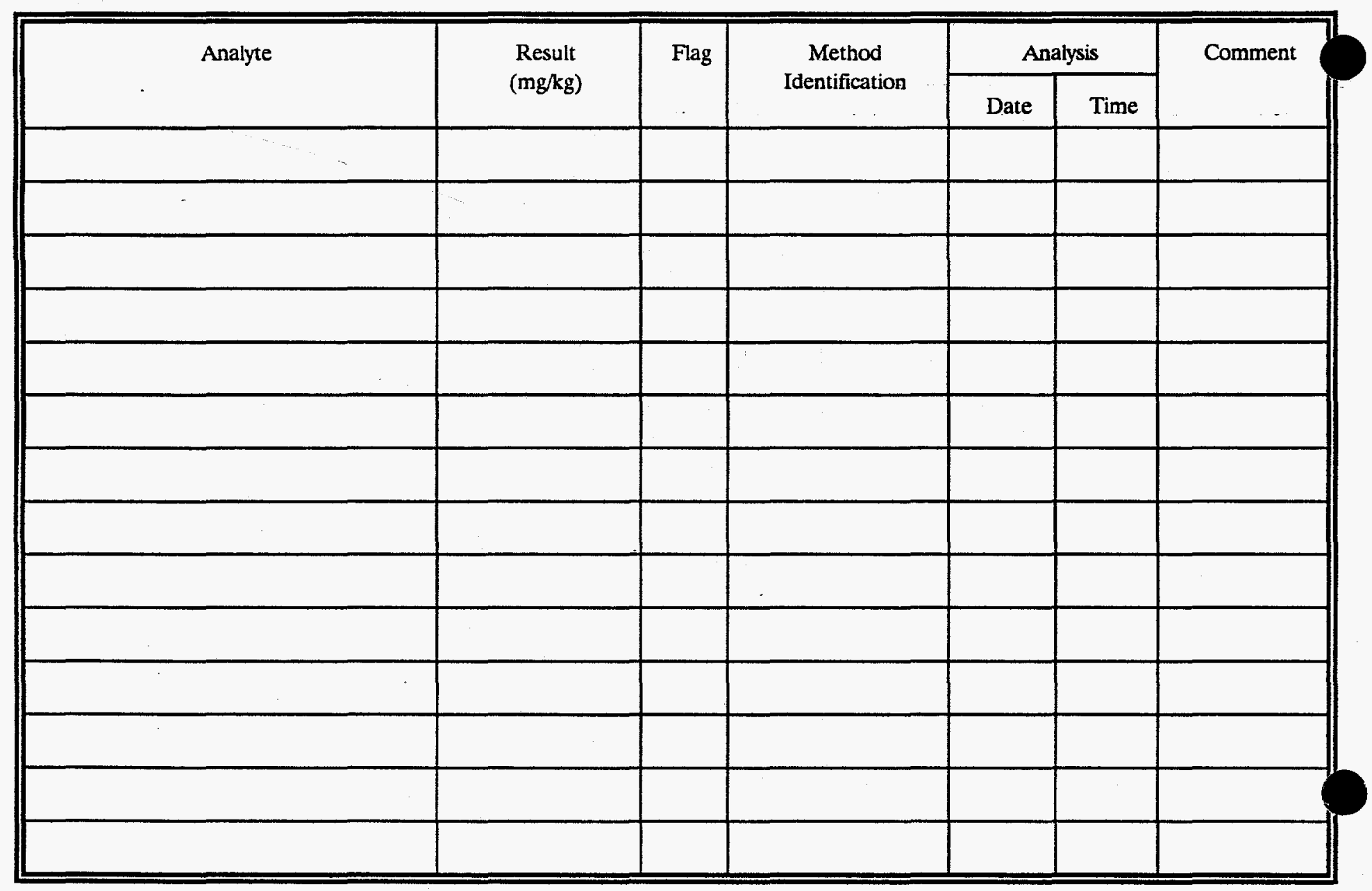

ADDITIONAL

COMMENTS:

APPROVAL: 